\title{
Poetical criticism of the view of nationalism in Kurdish Literature (Southern Kurmanji 1920-1970)
}

Dilshad Ali Mohamad ${ }^{1}$
Aso Omer Mustafa ${ }^{2}$

Received: Feb24, 2018 Reviewed: Mar24, 2018Accepted: Apr05, 2018

\begin{abstract}
ationalism is one of the significant initiates of poetical criticism in Kurdish literature during the years (1920-1970) AD, because in that period Kurdish nation faced very terrible political situations and Kurdistan's land was divided on four countries (Iraq, Iran, Turkey and Syria), therefore the declamation of poetical criticism at that time became national.Our research analyses those critical declamation that in the view of nationalism criticized the poetry texts and they have tried to analyse the texts according to this basis, national critics declared that any text focused on nationalism and the issues and objects of nationalism, was good and successful, but any text did not focus on nationalism and the issues and objects of nationalism, was not good and weak. So, these critics encouraged the poets to write those texts that express the trend of Kurdish nation. Our research consists of two chapters: first chapter (poetical criticism in the view of nationalism from 1920 to 1970), it gets those critical declamation which written in that time, and the second chapter (poetical criticism in the view of nationalism after the revolution of 14 July 1958 until 1970, it gets those critical declamation which written in that time.At the end the result expressed in some points.
\end{abstract}

Keywords:Poetry criticism, National criticism, Self poetry, Nationalism poetry

\section{Recommended citation:}

Mohamad,D. A. \&Mustafa,A. O. (2018). Poetical criticism of the view of nationalism in Kurdish Literature (Southern Kurmanji 1920-1970). International Journal of Kurdish Studies 4 (2), 478 - 489. doi: 10.21600 / ijoks.454469

\footnotetext{
${ }^{1}$ Prof. Dr., Department of Kurdish Language, College of Language , Sulaimani University, Sulaimani, KRG, Iraq. E-mail: Dilshad.Mohamad@univsul.edu.iq

${ }^{2}$ Asst. Lecturer, Department of Kurdish Language, College of Language, Sulaimani University, Sulaimani, KRG, Iraq. E-mail: aso.omar@charmouniversity.org
} 


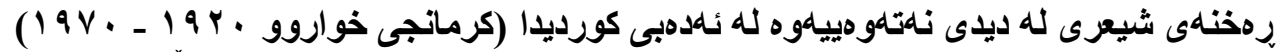

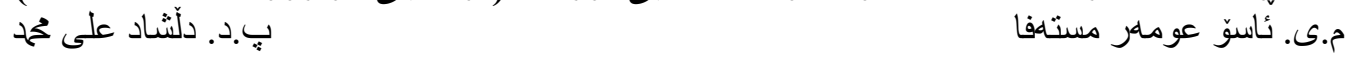

بِيَشْكى

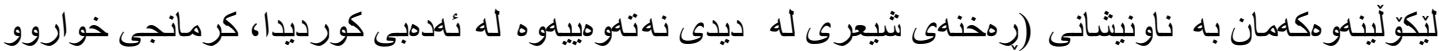

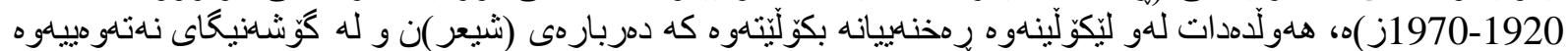

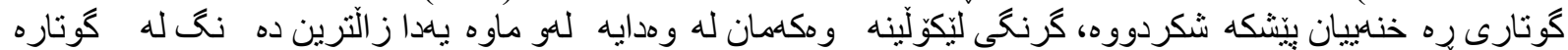

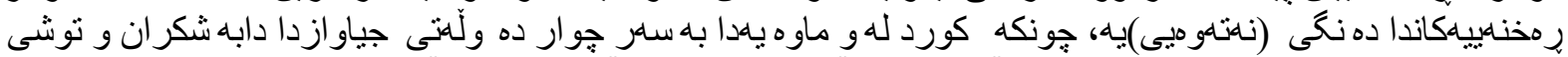

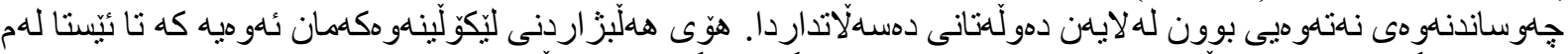

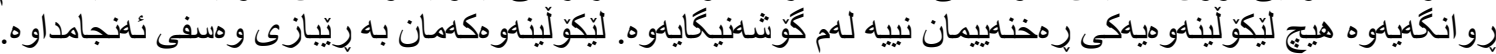

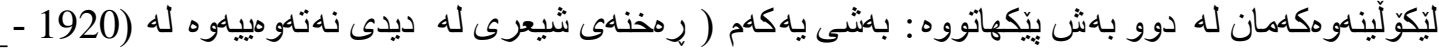

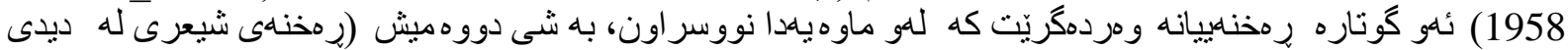

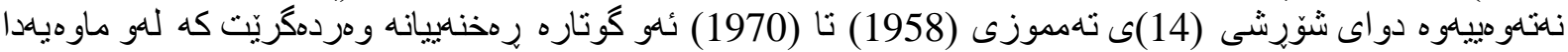

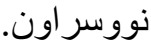

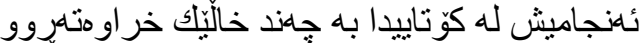

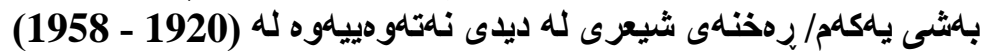

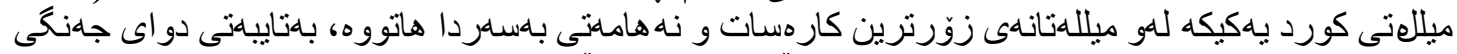

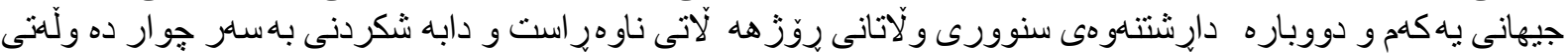

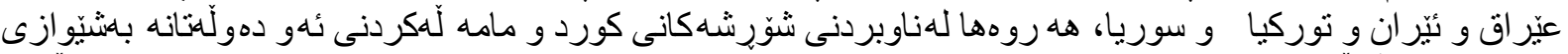

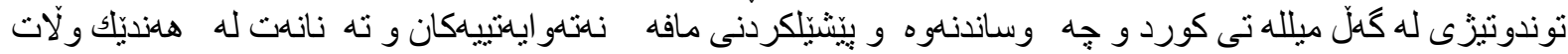

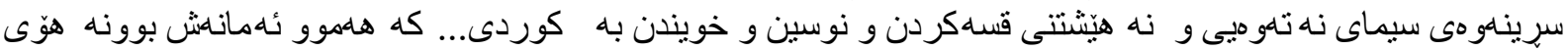

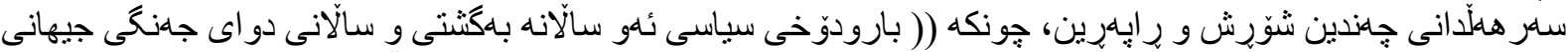

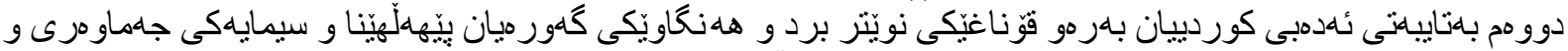

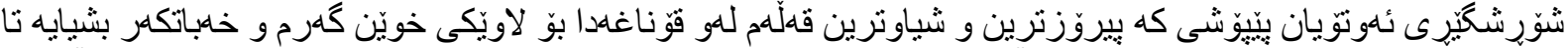

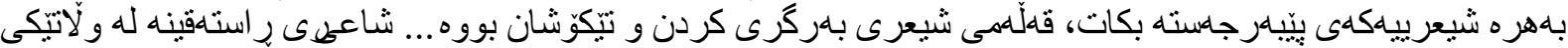

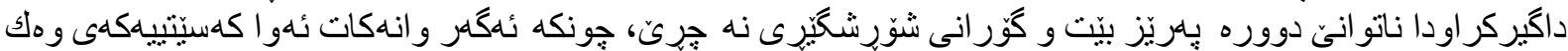

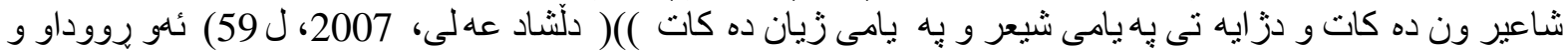

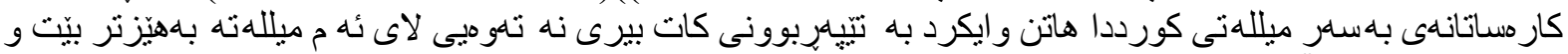

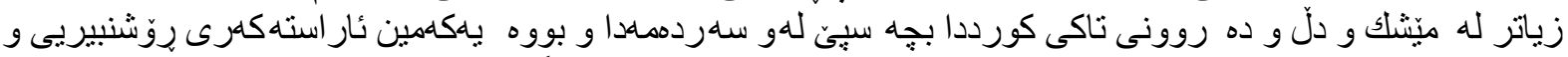

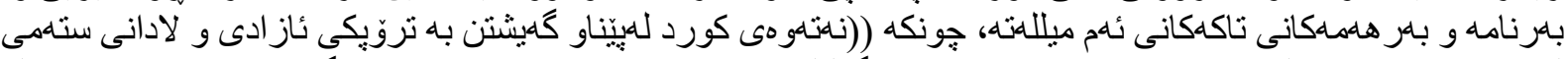

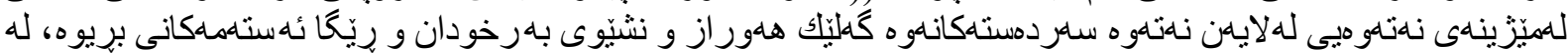

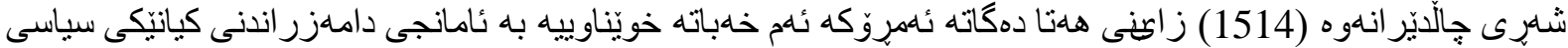

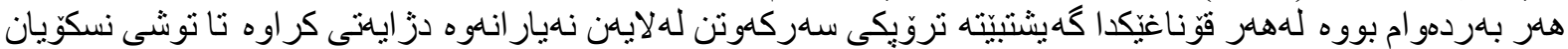

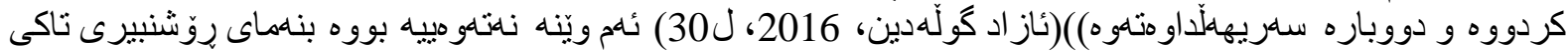

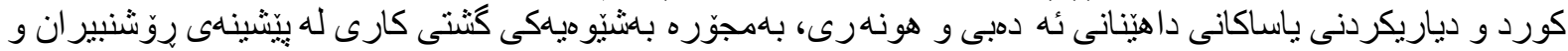

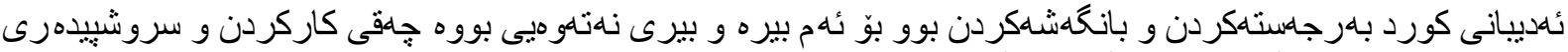

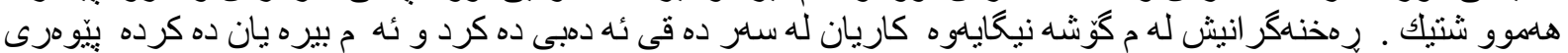

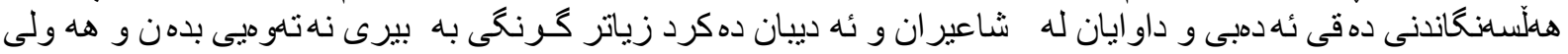
سار خستنى بدهن.

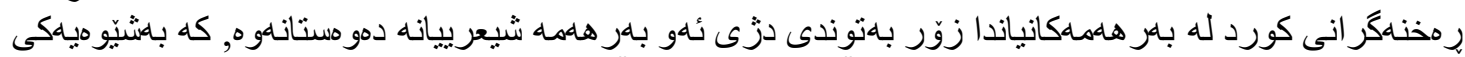

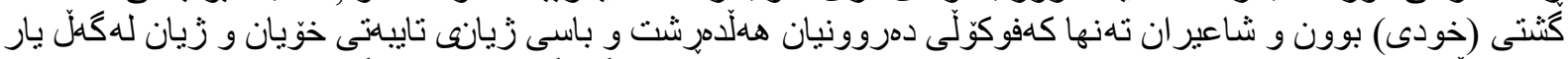

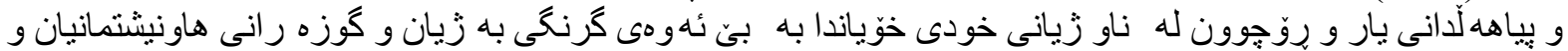

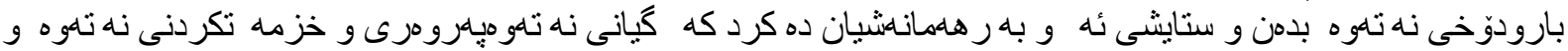

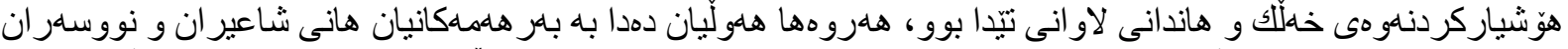

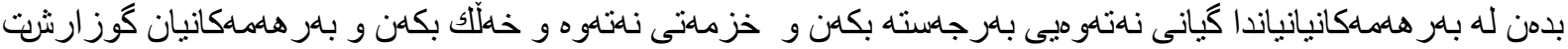

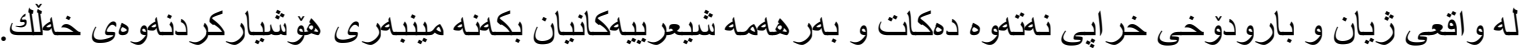




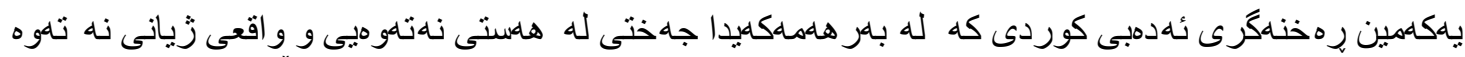

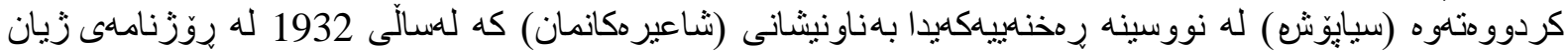

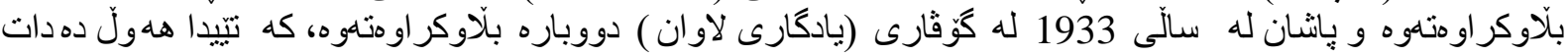

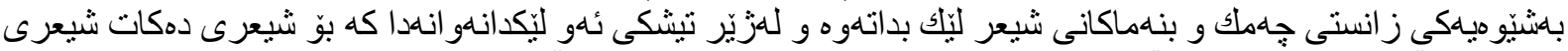

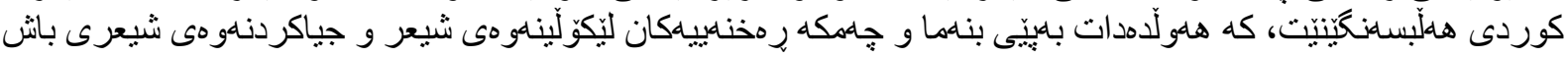

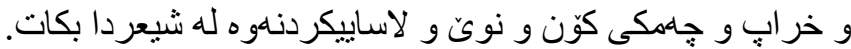

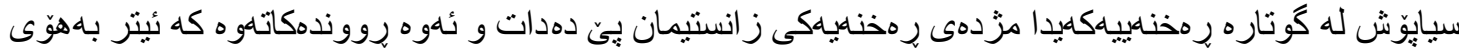

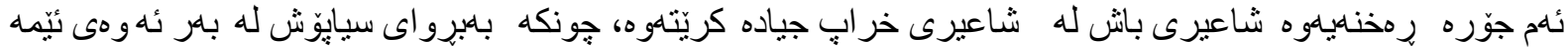

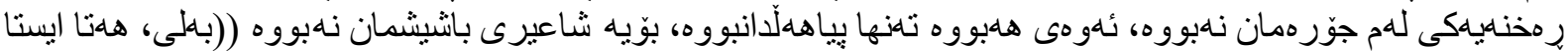

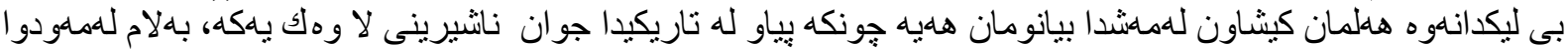

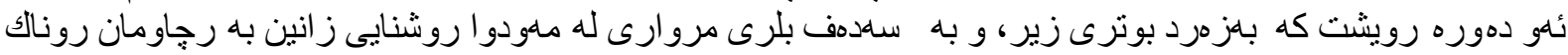

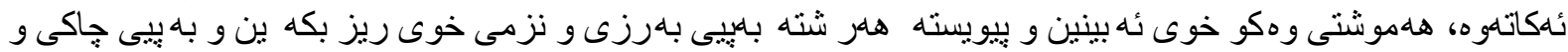

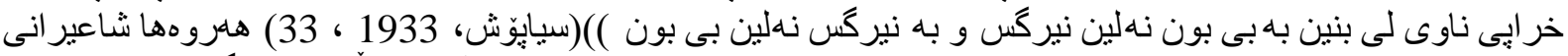

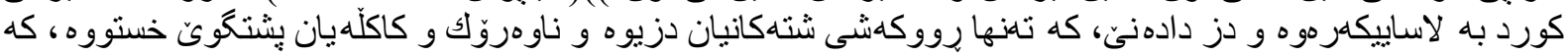

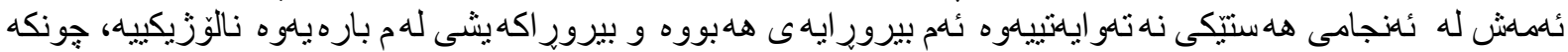

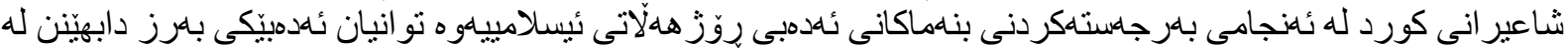

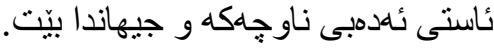

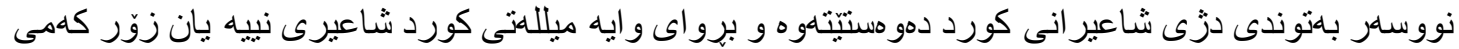

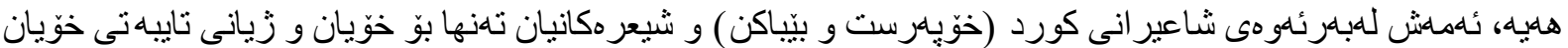

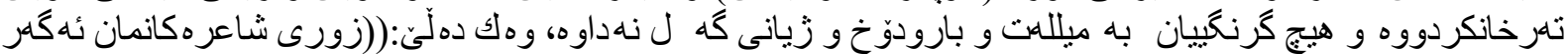

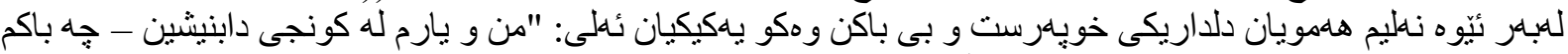

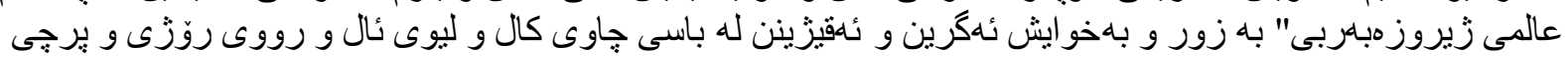

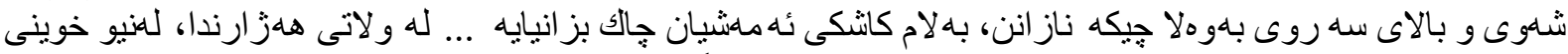

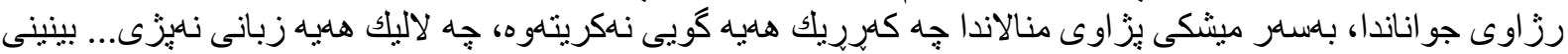

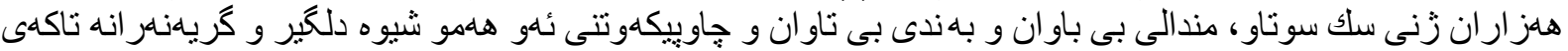

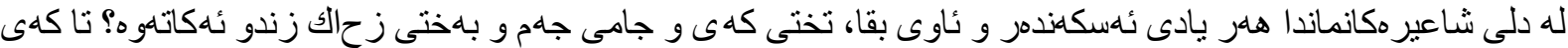

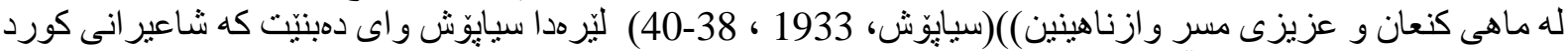

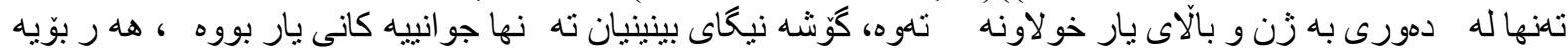

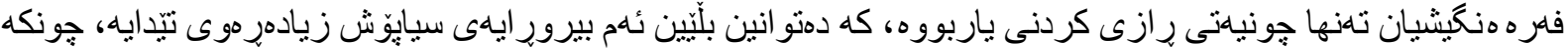

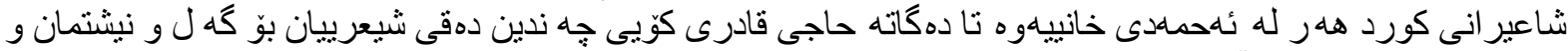

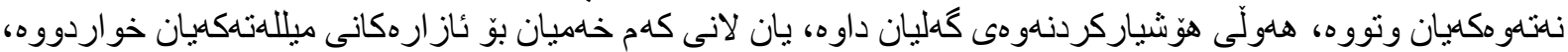

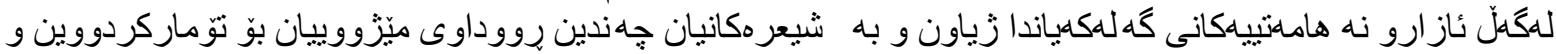

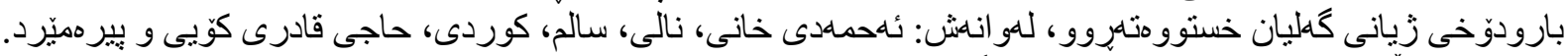

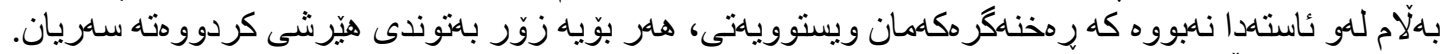

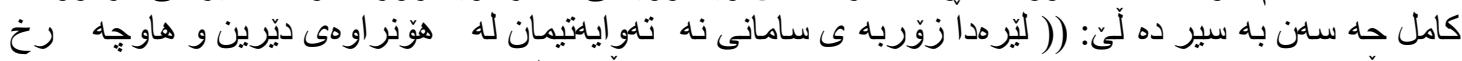

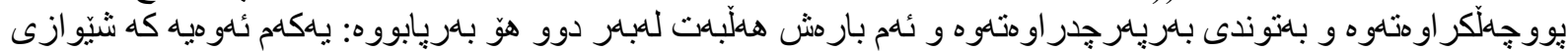

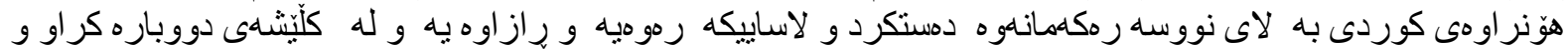

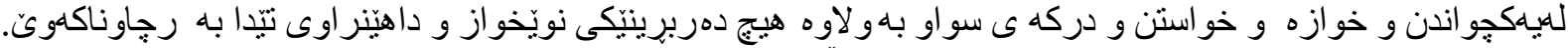

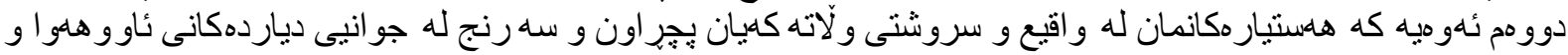

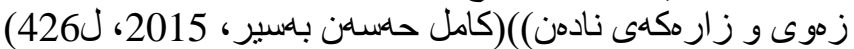

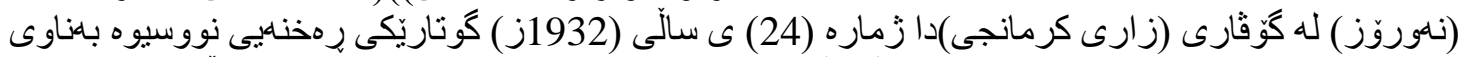

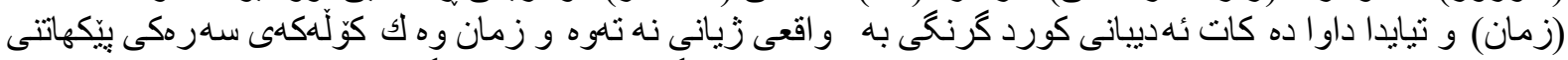

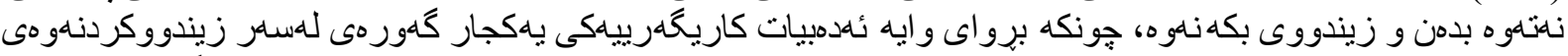

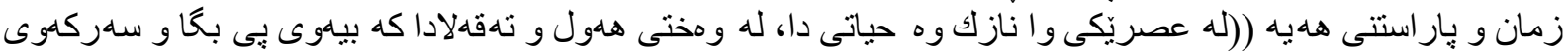

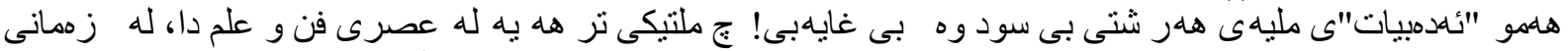

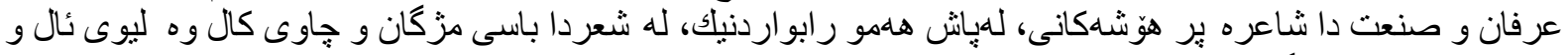

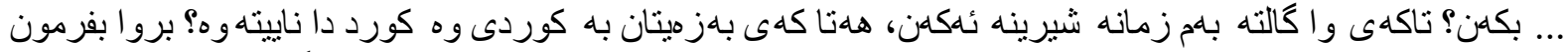

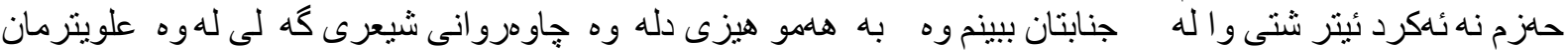

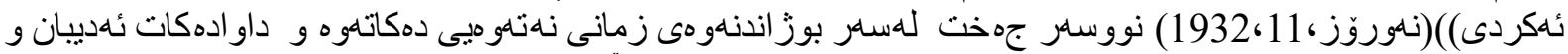

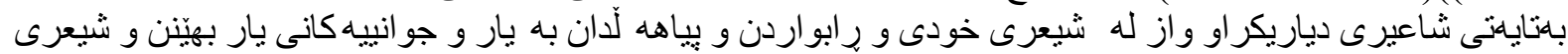




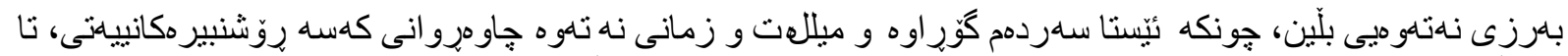

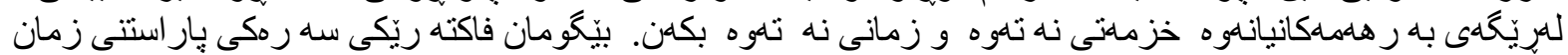

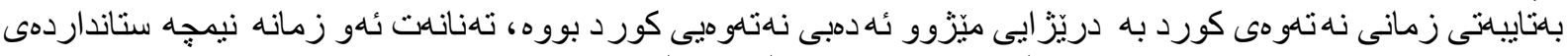

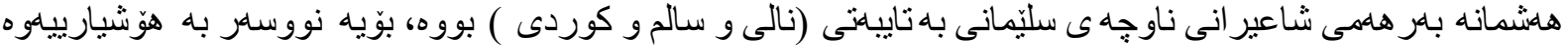

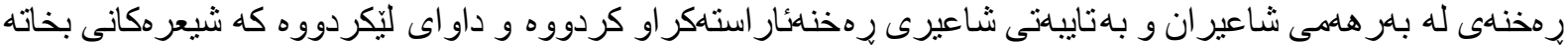

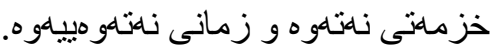

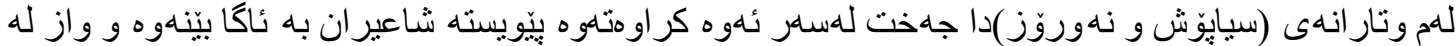

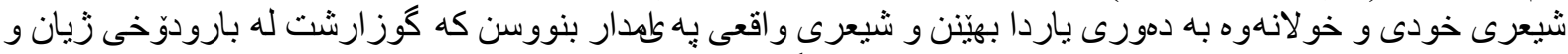

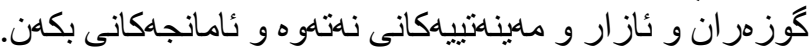

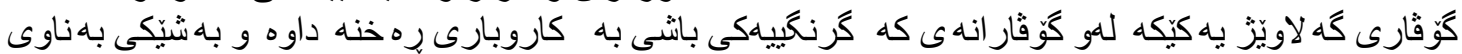

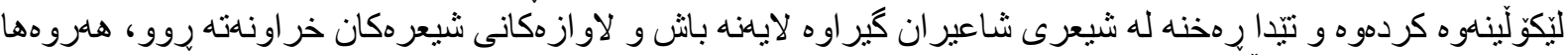

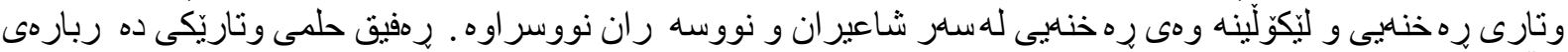

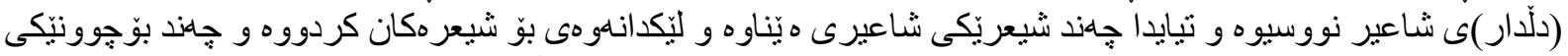

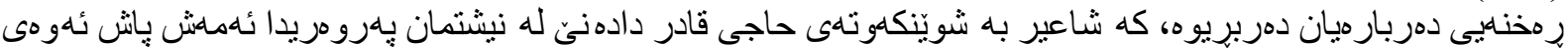

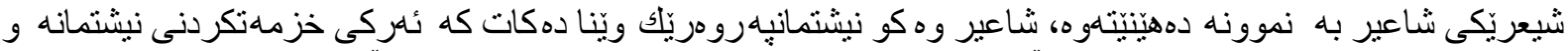

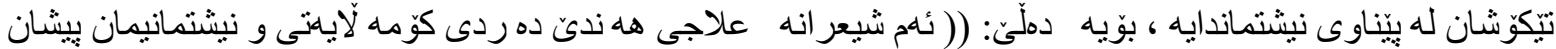

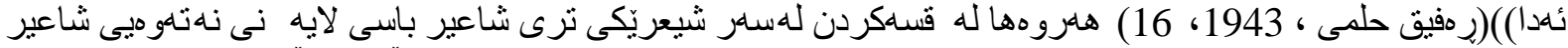

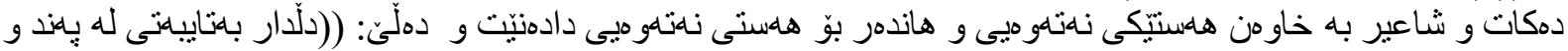

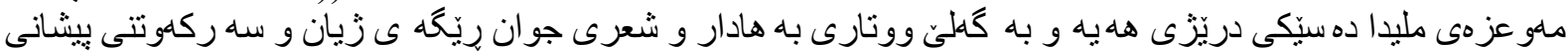

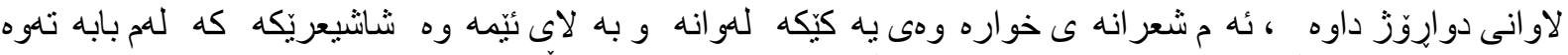

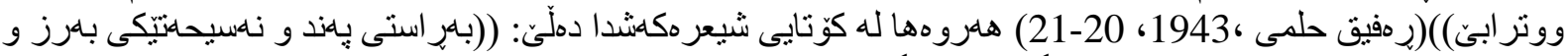

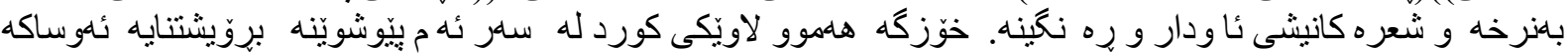

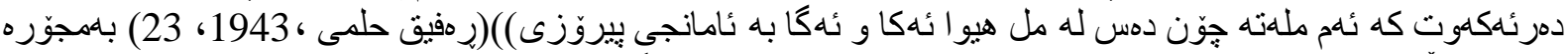

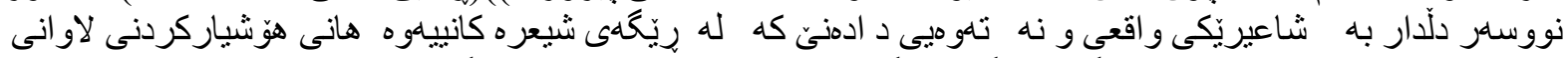

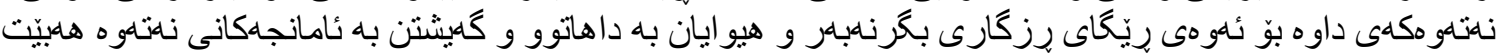

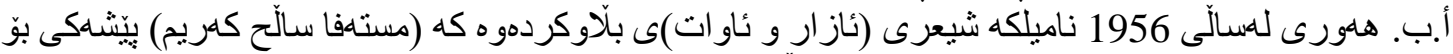

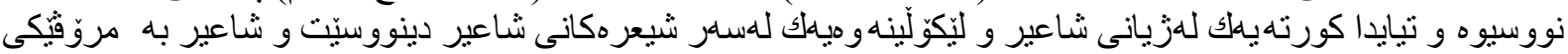

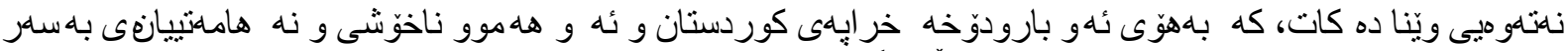

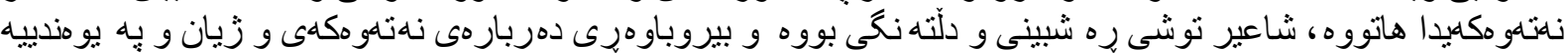

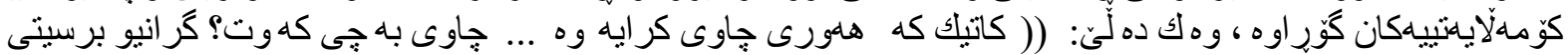

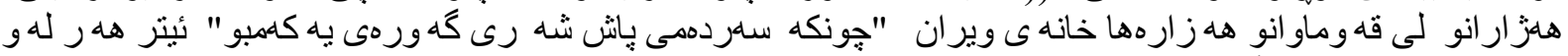

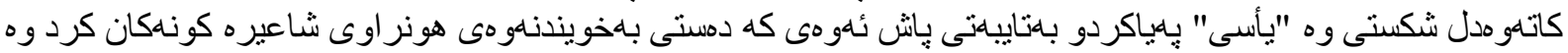

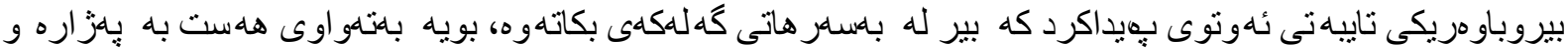

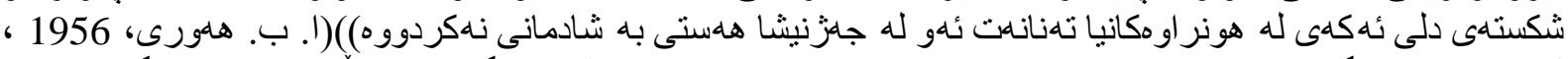

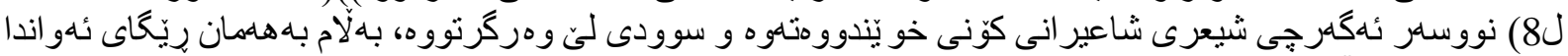

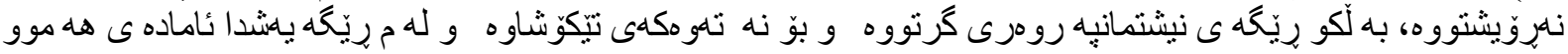

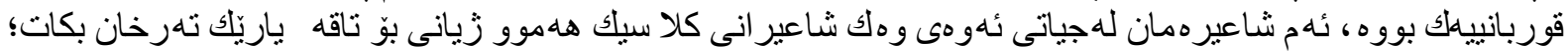

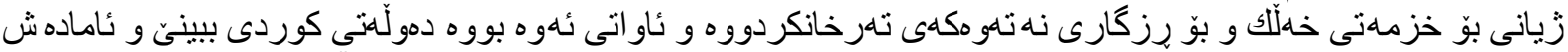

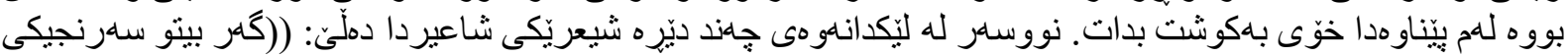

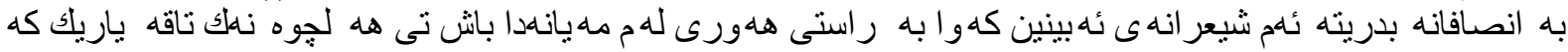

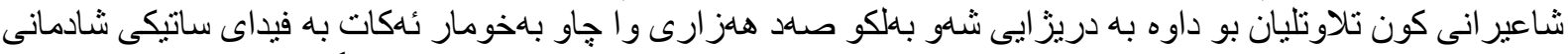

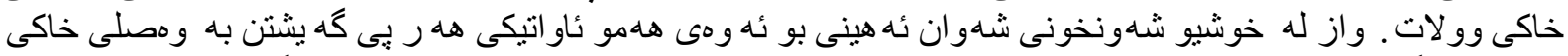

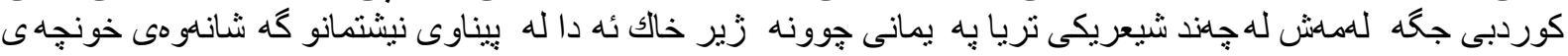

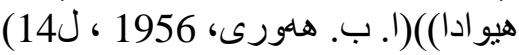

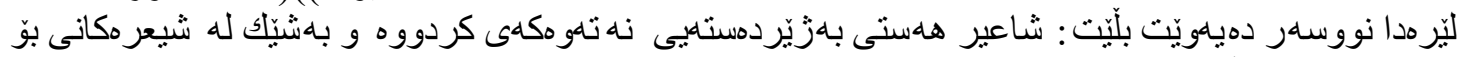

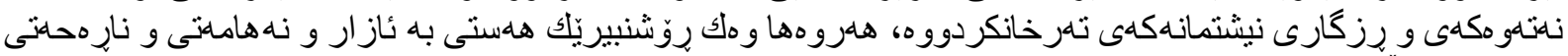

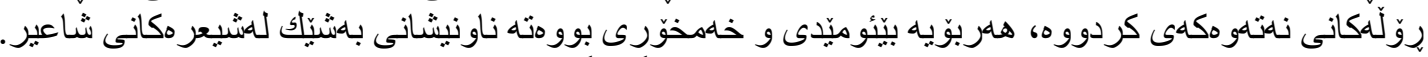

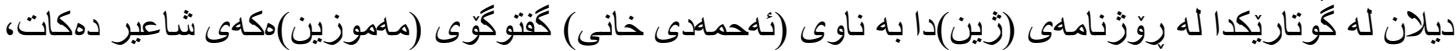

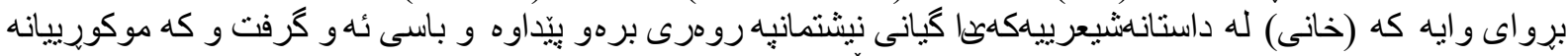

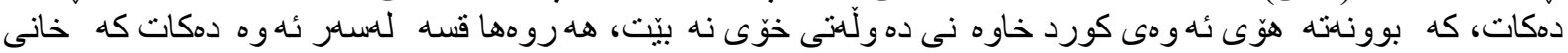




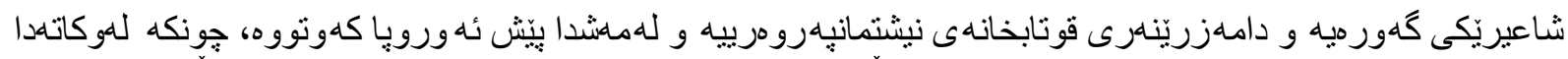

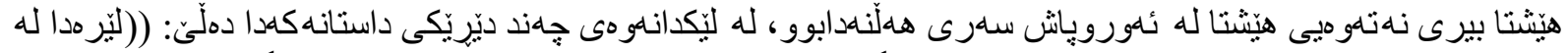

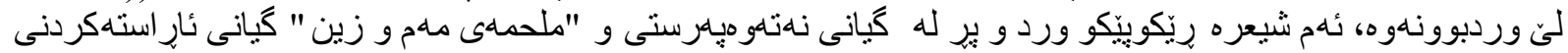

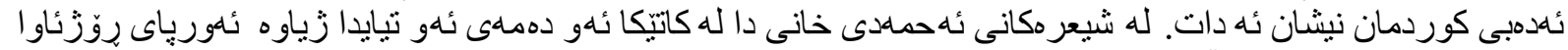

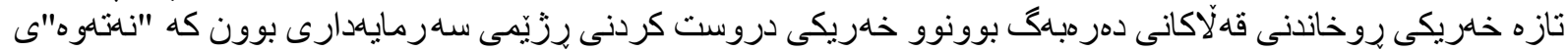

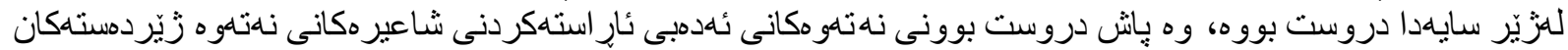

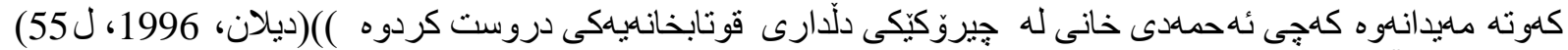

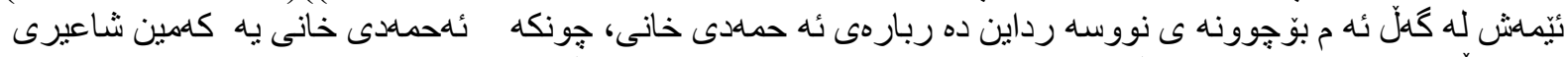

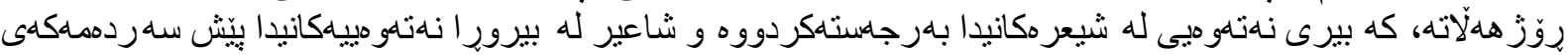
خوّى كهوتووها

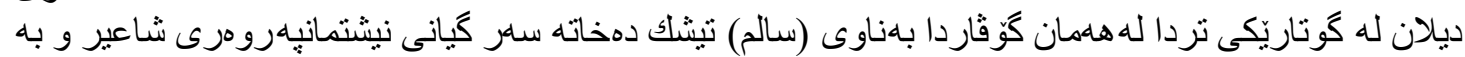

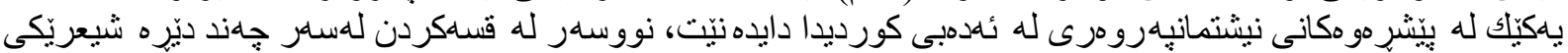

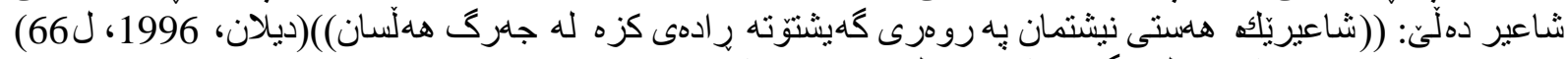

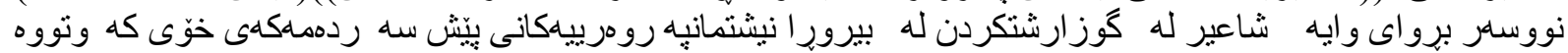

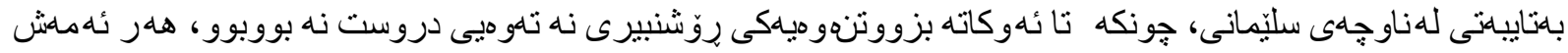

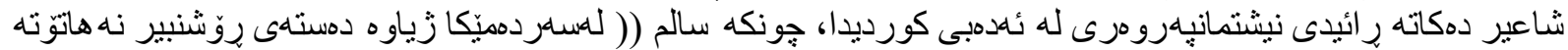

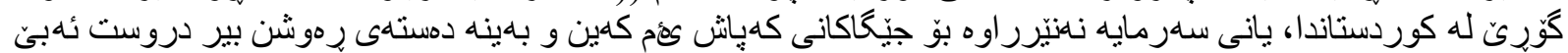

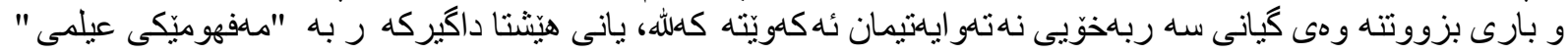

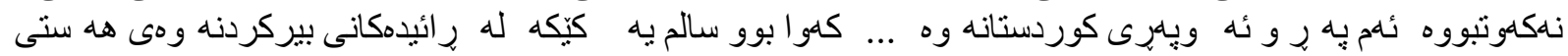

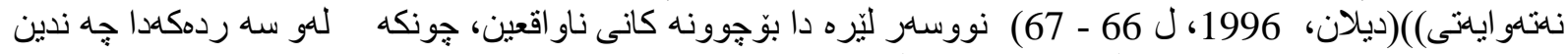

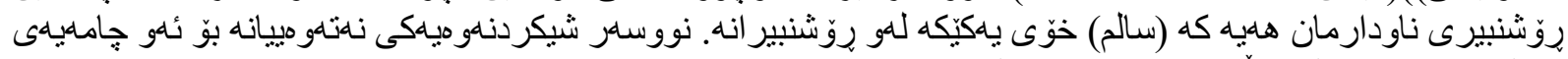

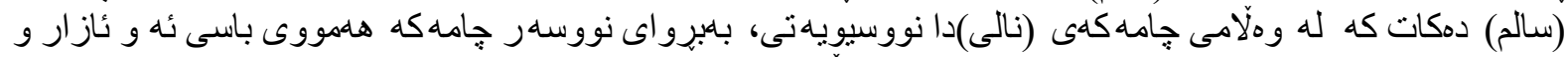

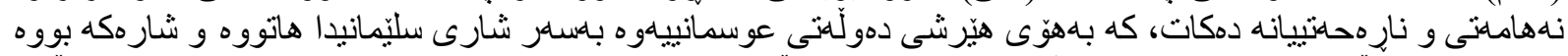

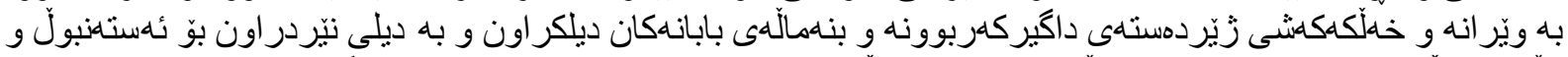

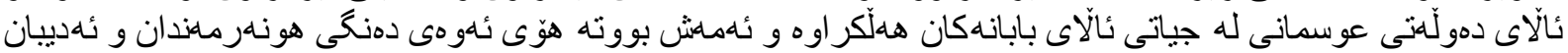

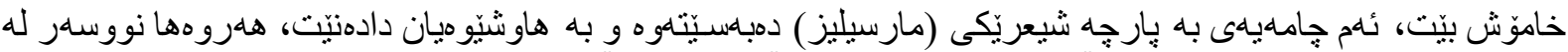

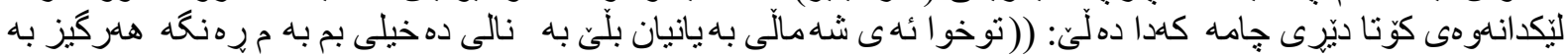

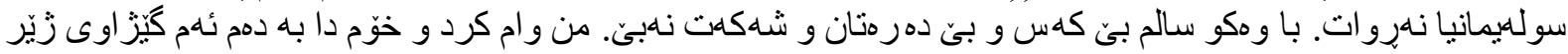

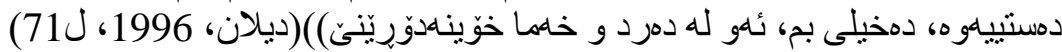

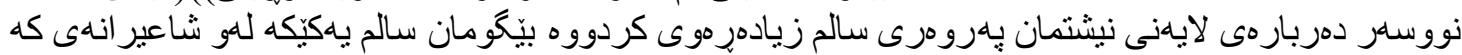

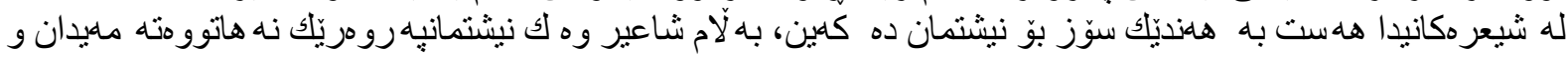

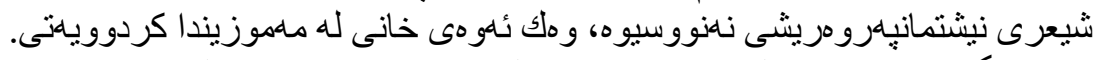

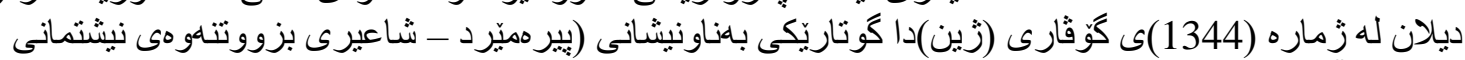

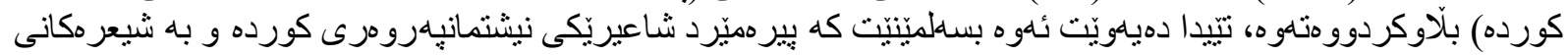

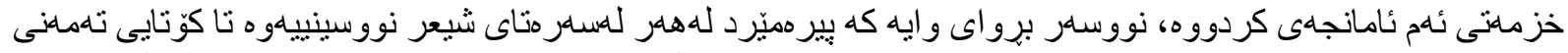

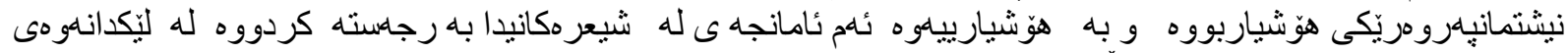

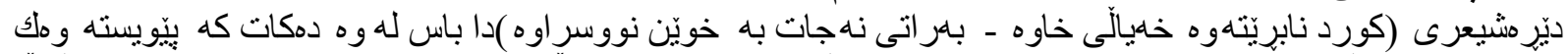

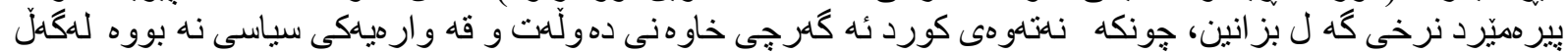

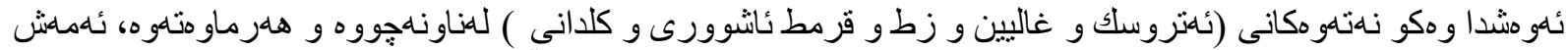

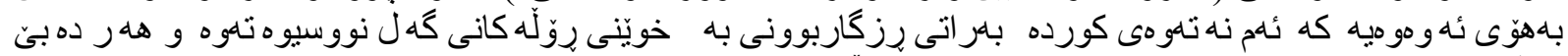

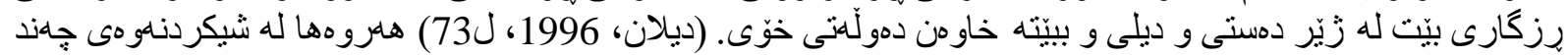

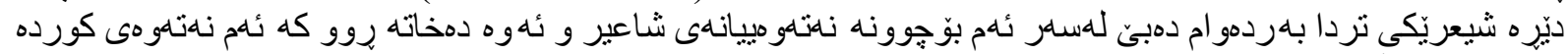

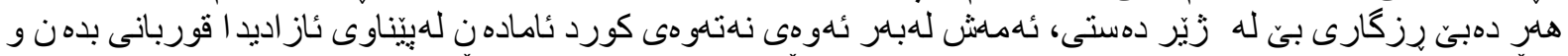

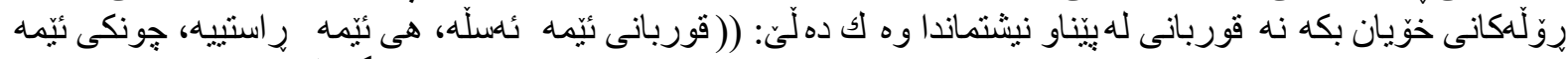

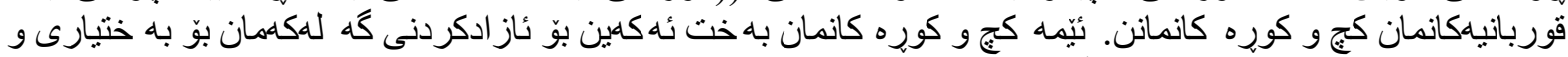

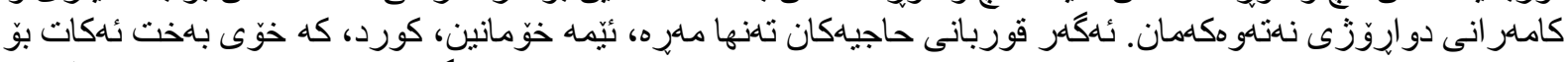

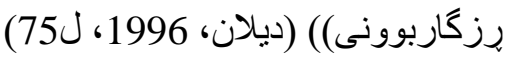

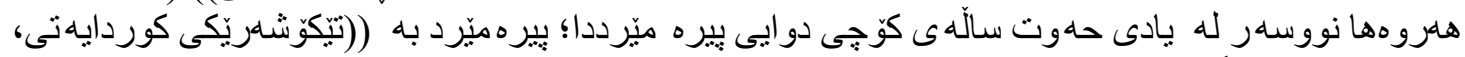

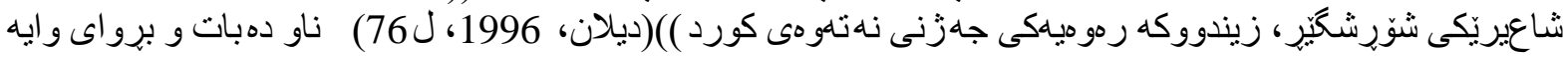

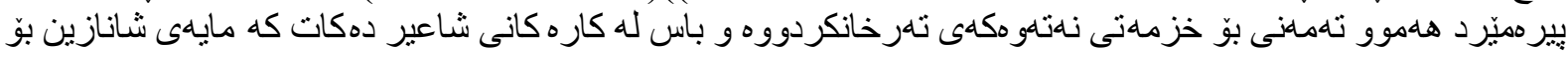




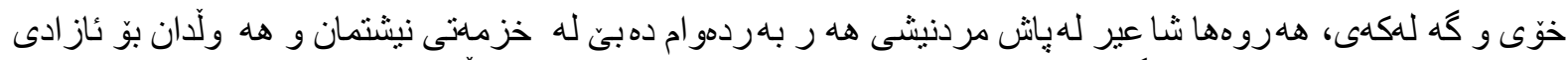

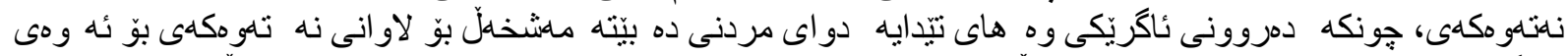

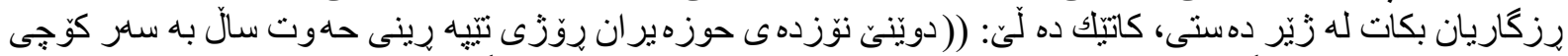

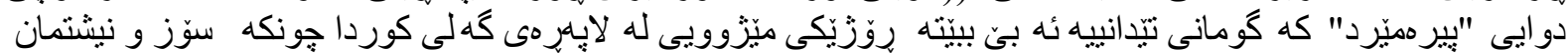

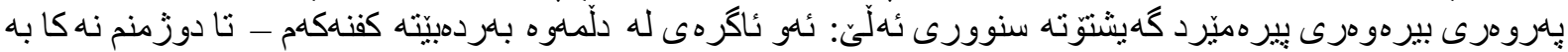

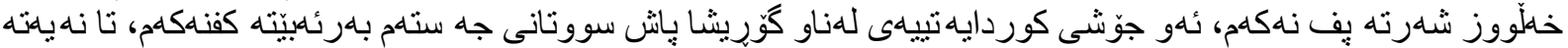

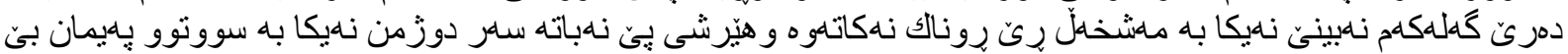

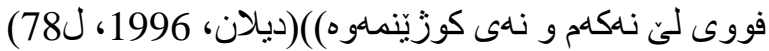

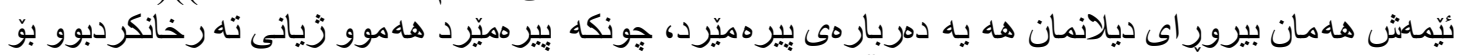

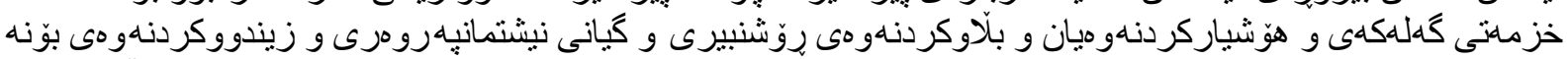

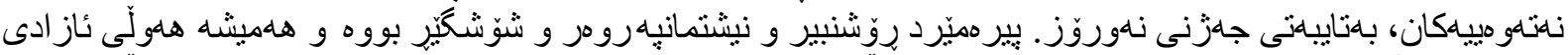

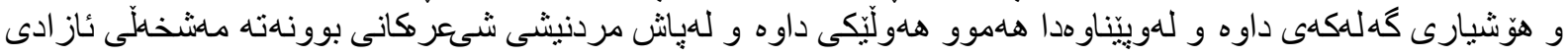

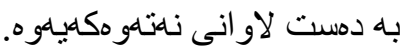

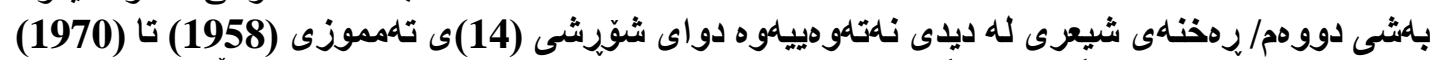

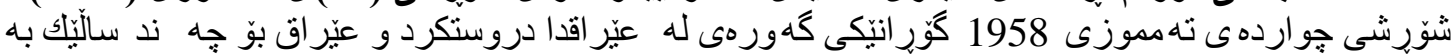

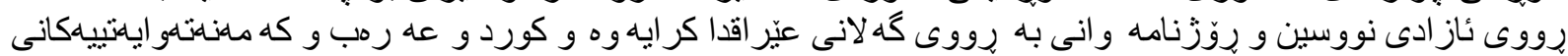

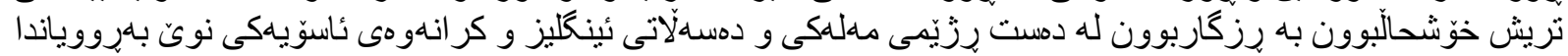

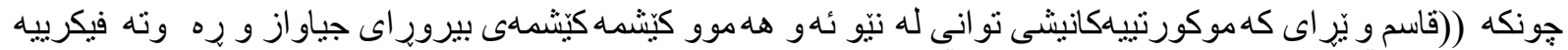

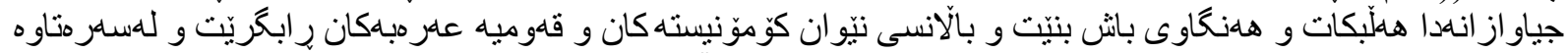

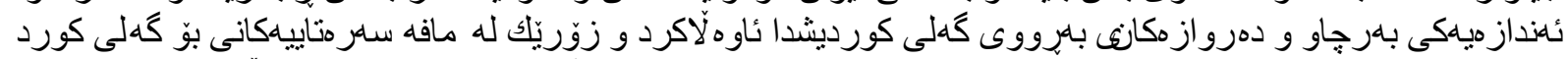

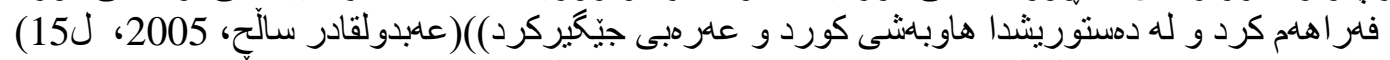

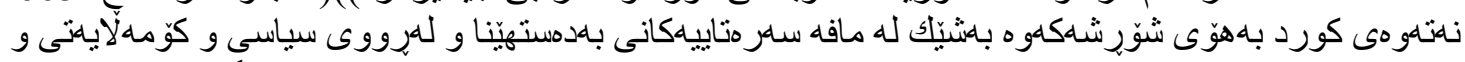

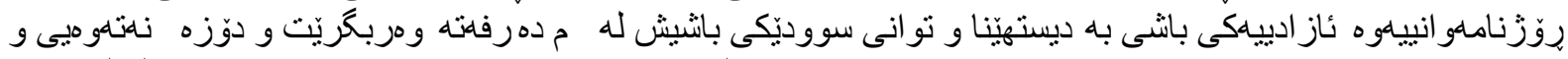

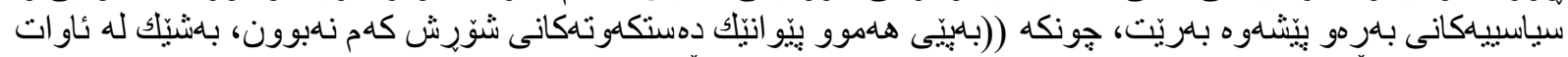

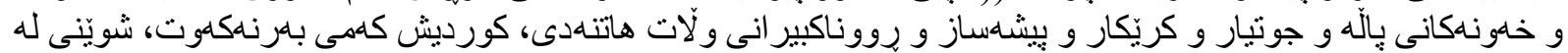

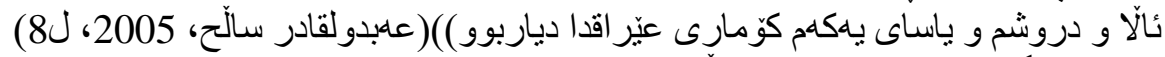

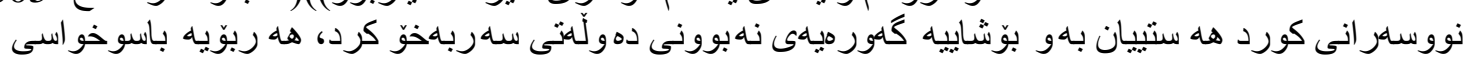

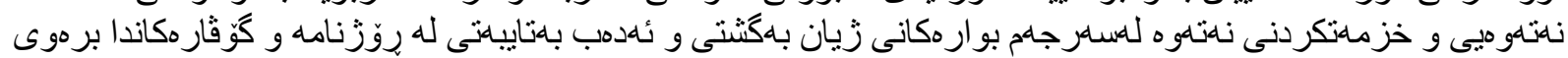

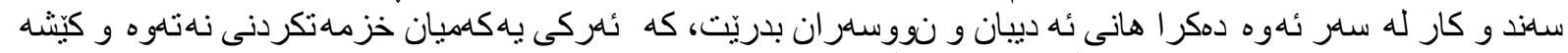

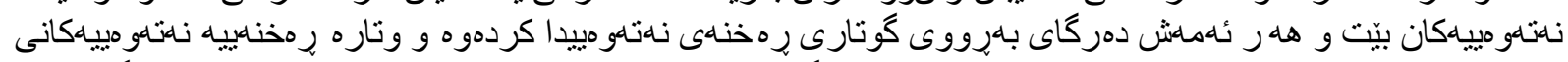

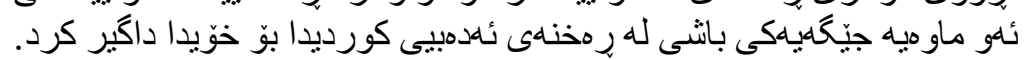

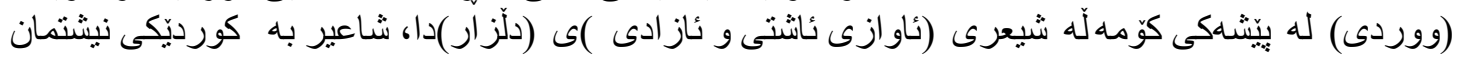

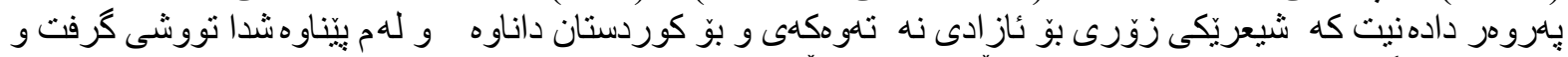

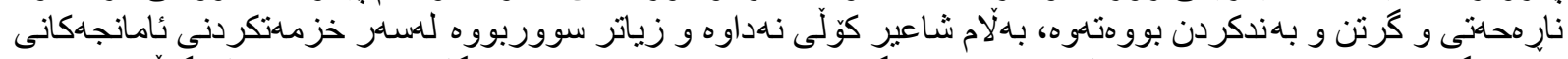

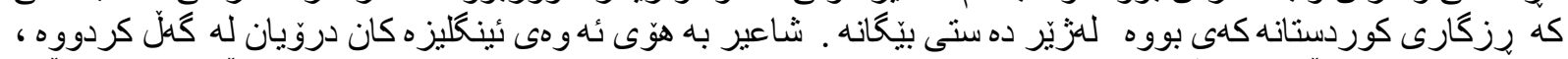

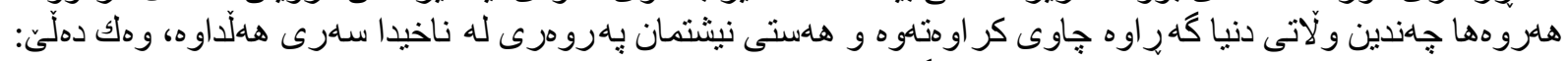

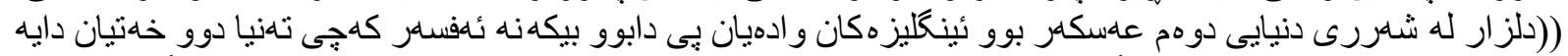

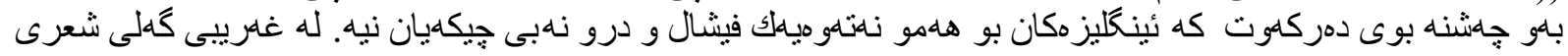

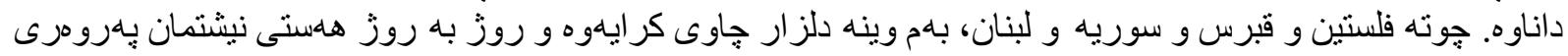

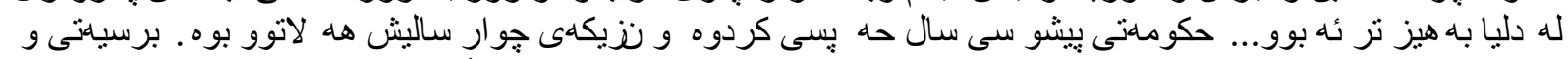

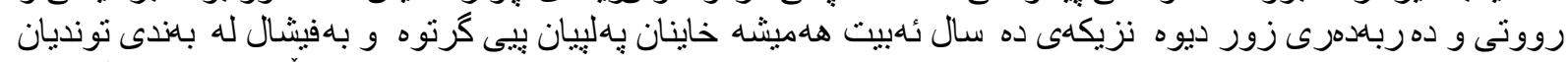

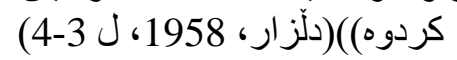

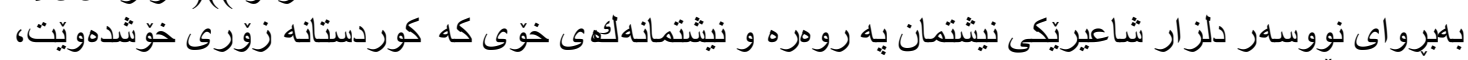

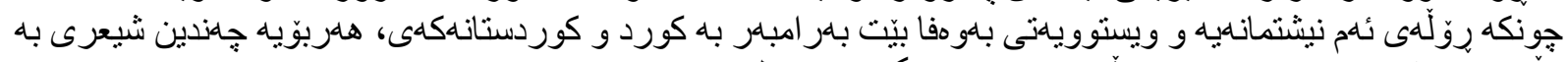

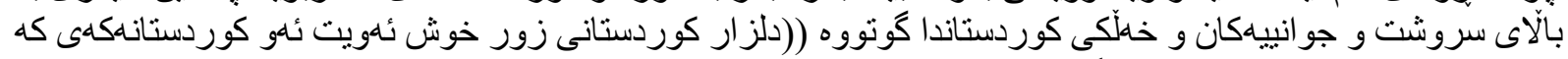

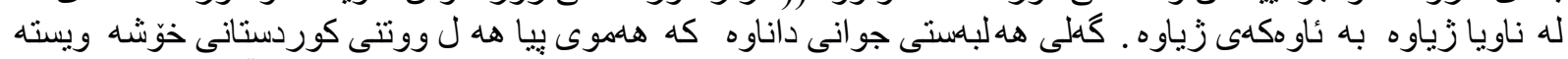

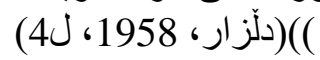

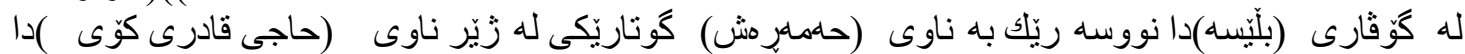

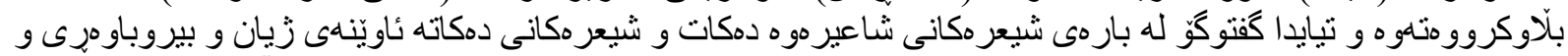

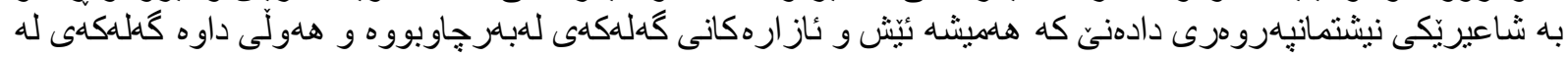




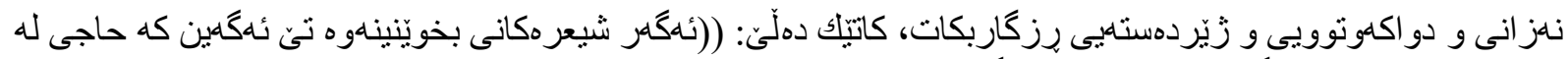

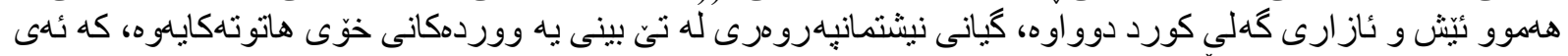

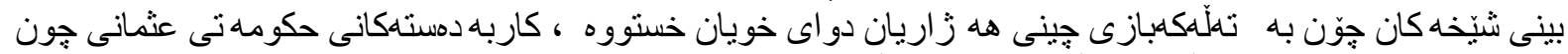

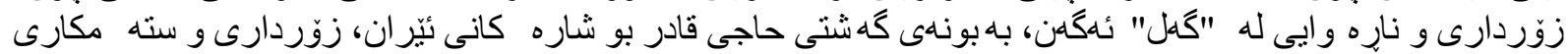

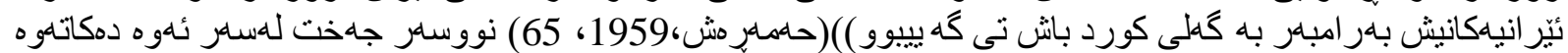

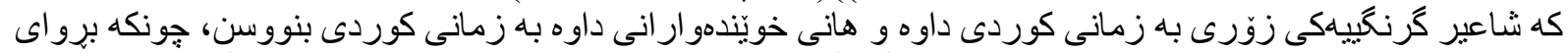

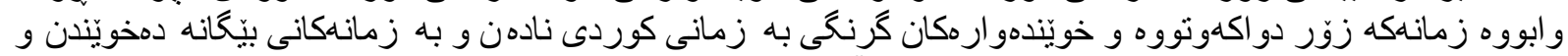

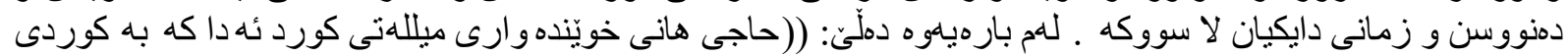

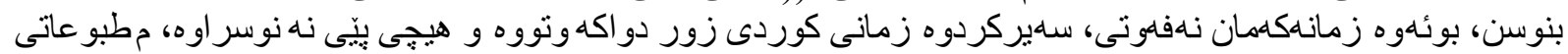

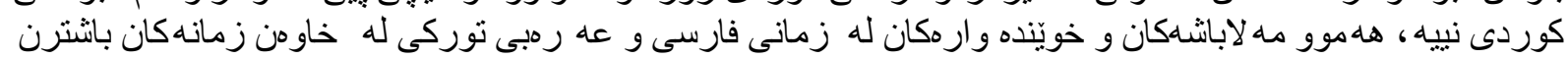

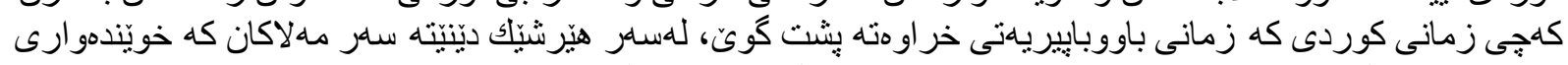

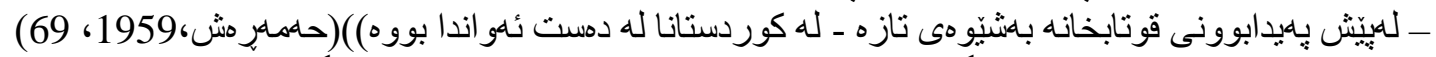

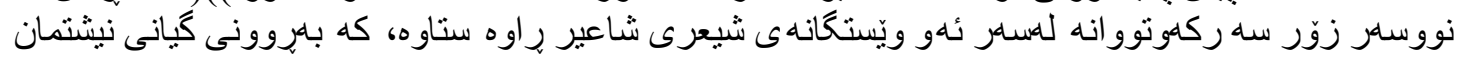

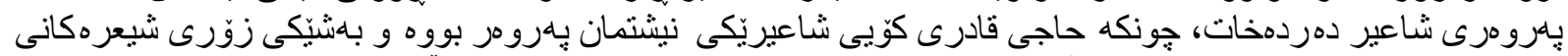

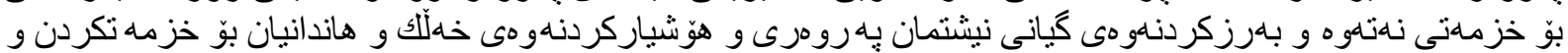

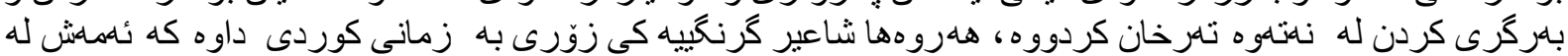

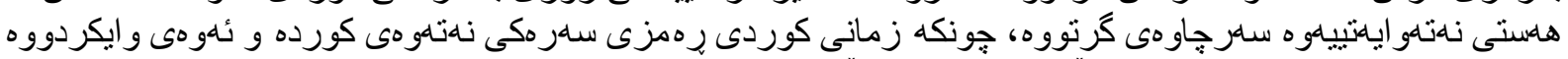

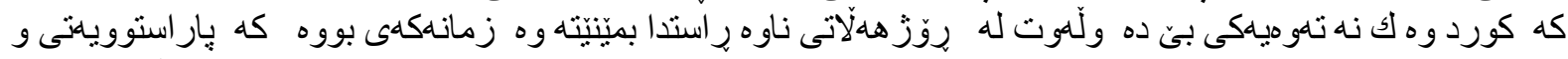

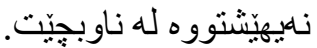

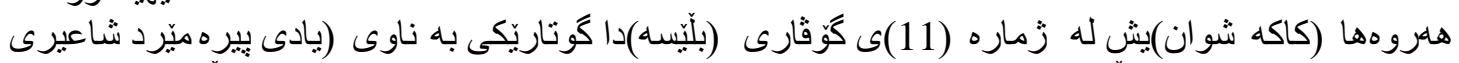

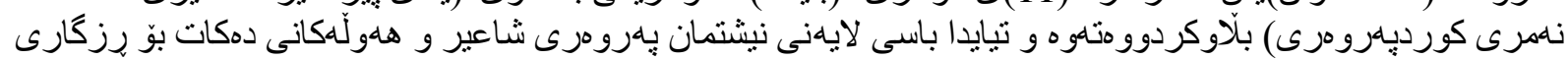

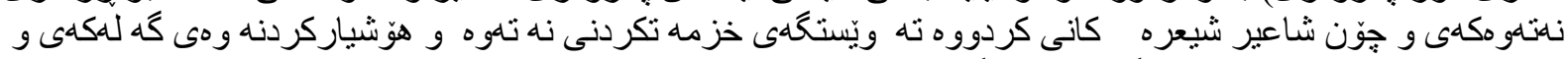

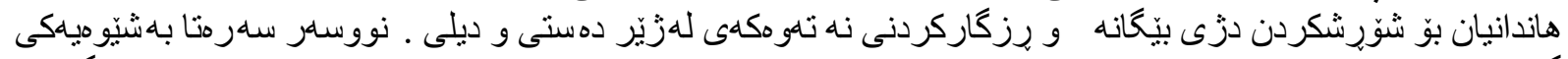

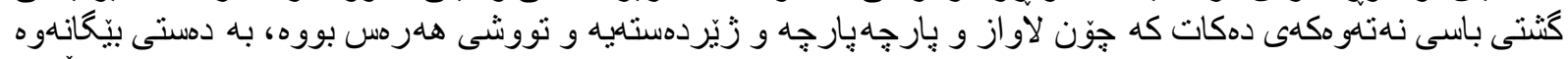

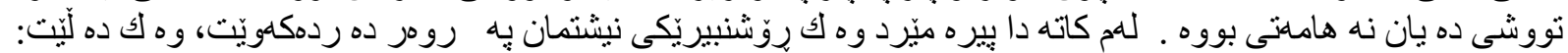

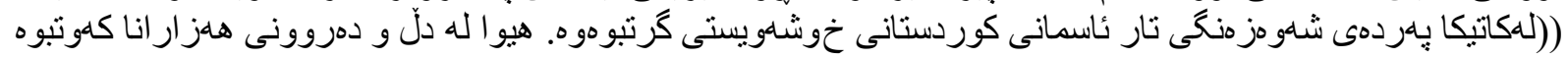

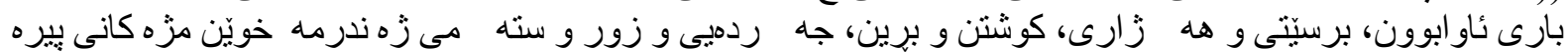

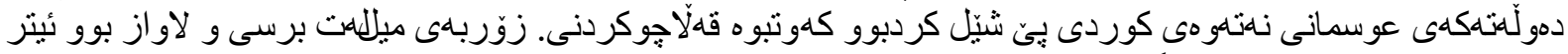

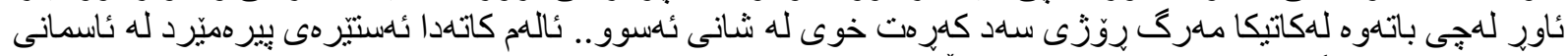

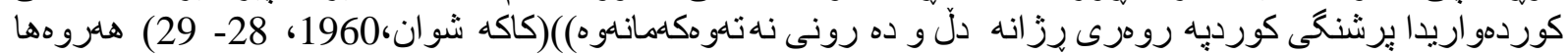

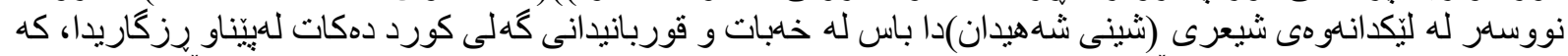

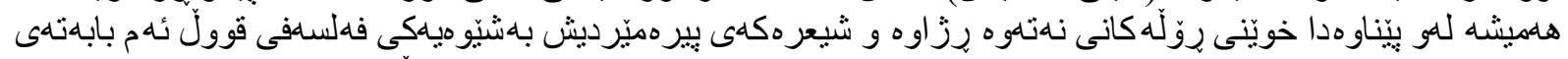

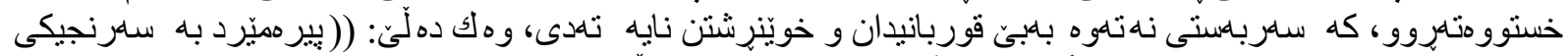

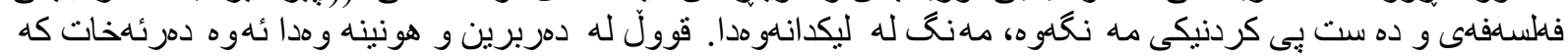

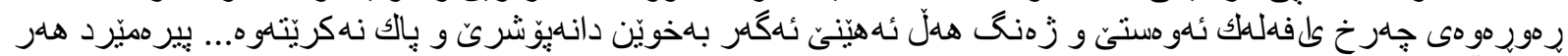

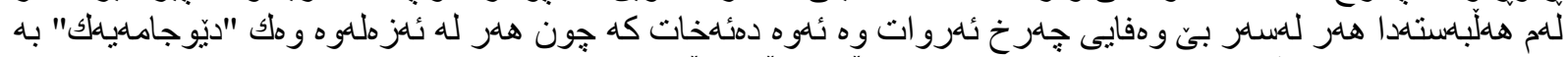

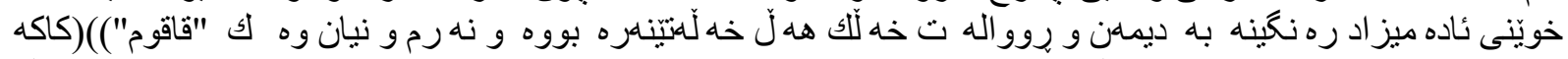

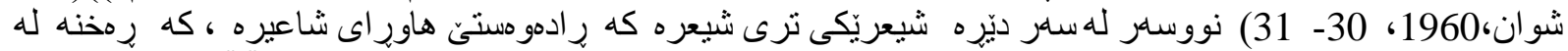

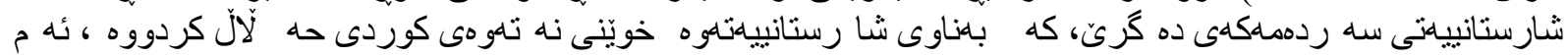

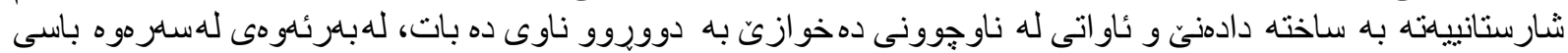

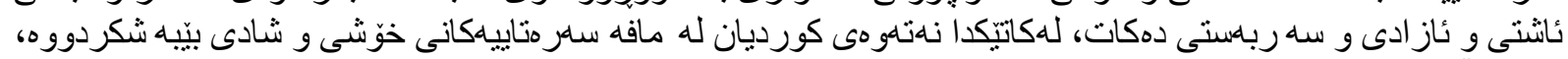

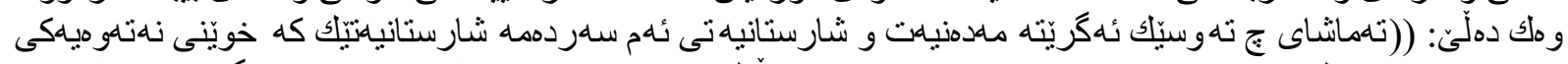

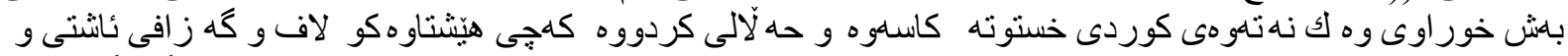

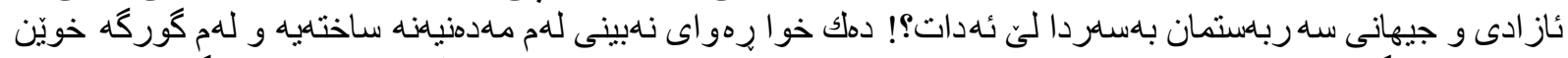

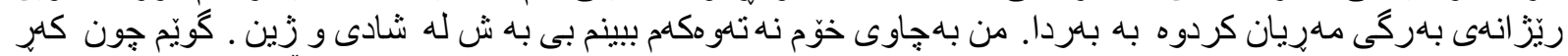

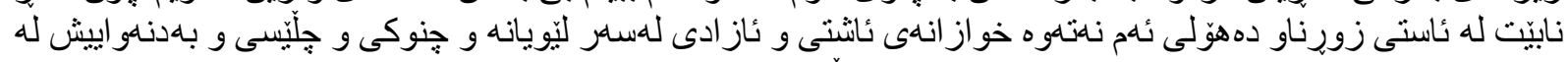

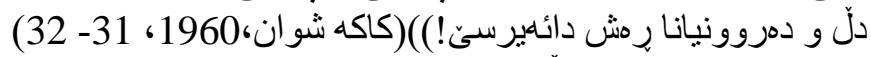

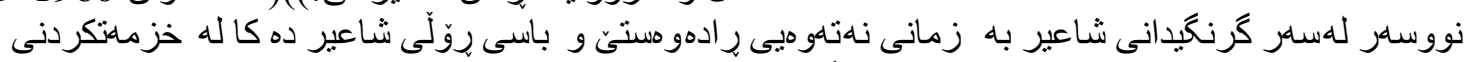

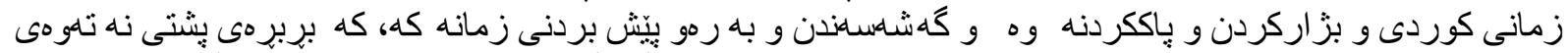

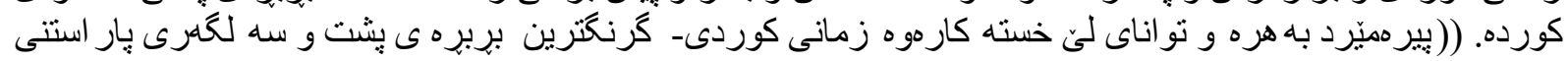




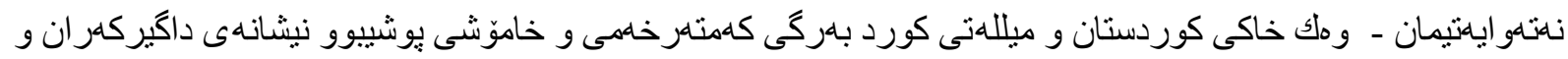

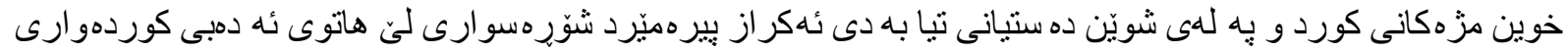

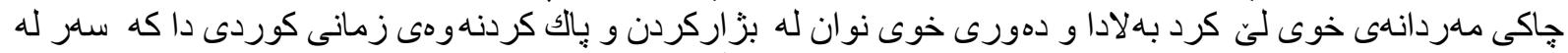

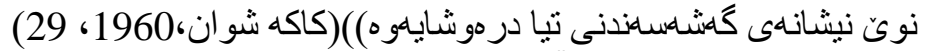

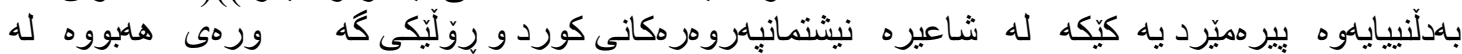

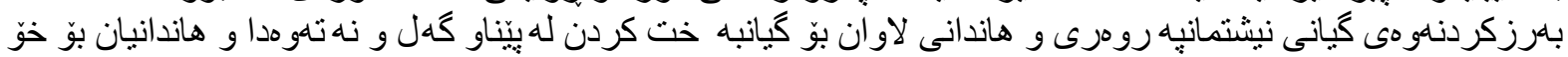

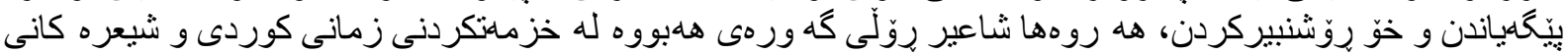

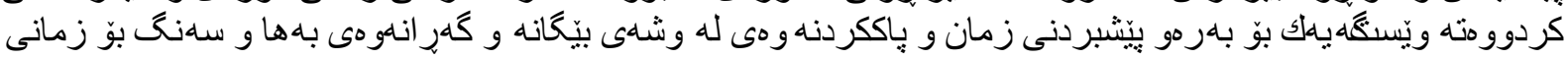

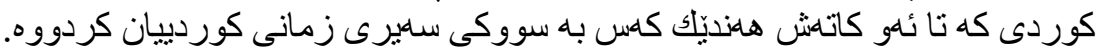

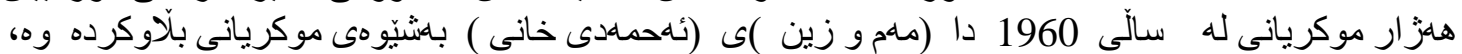

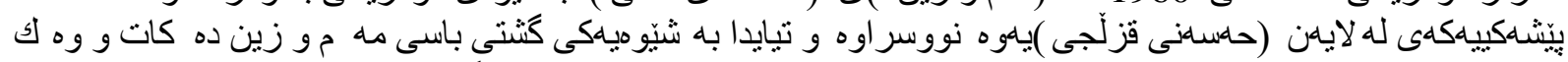

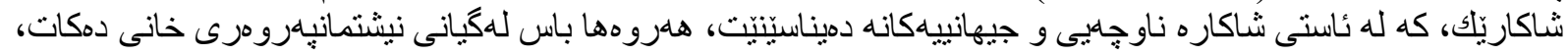

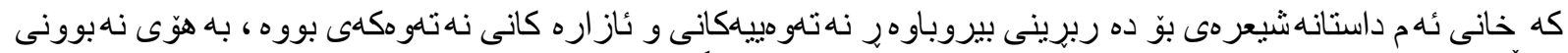

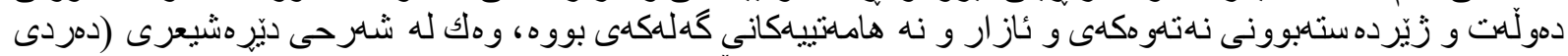

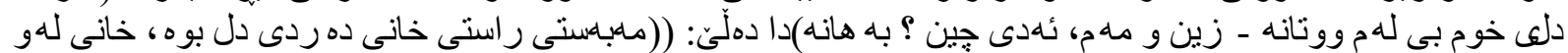

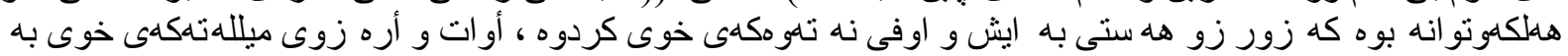

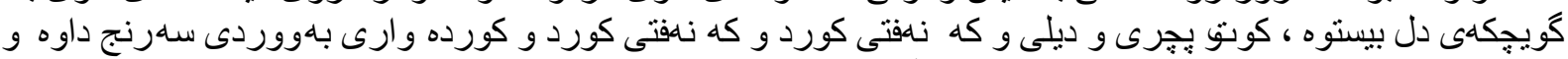

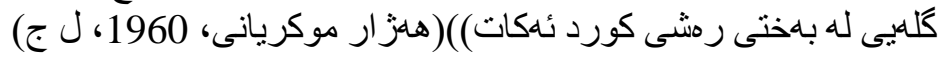

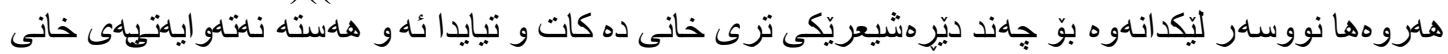

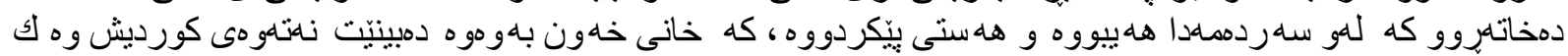

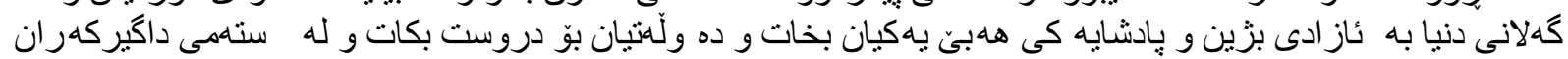

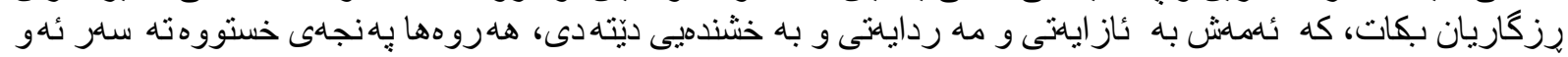

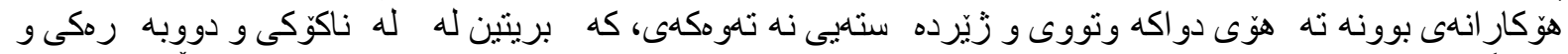

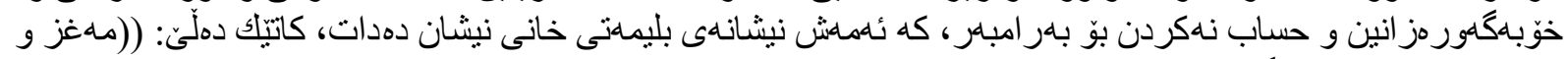

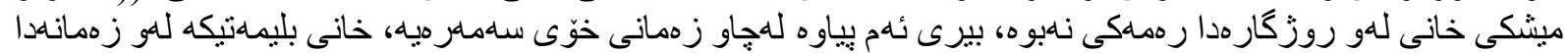

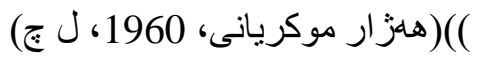

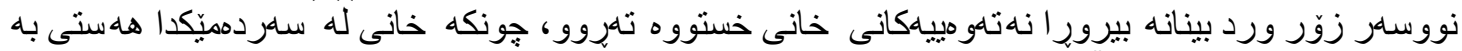

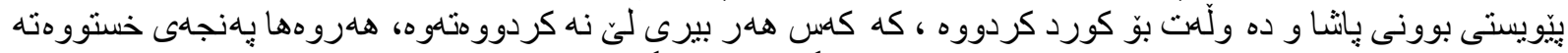

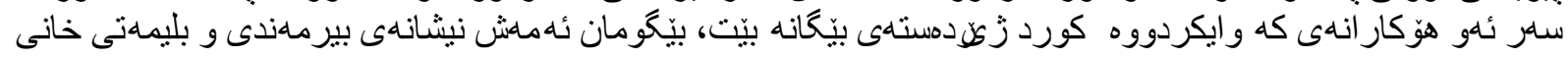

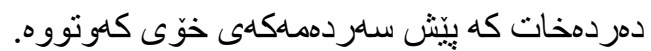

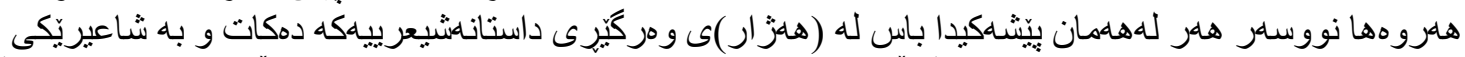

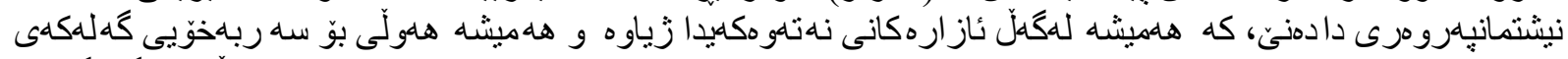

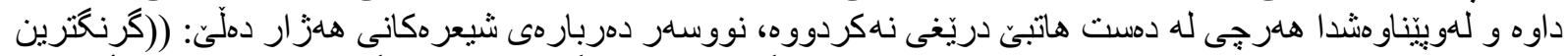

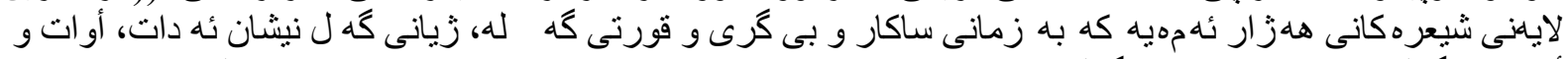

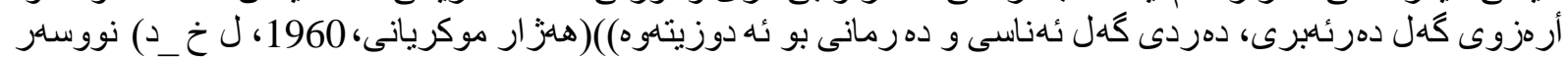

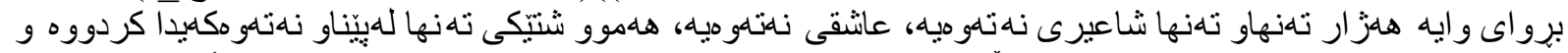

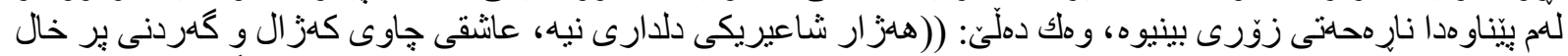

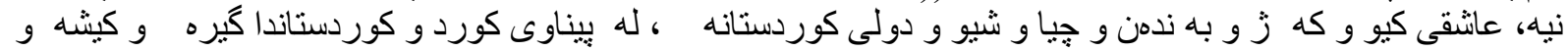

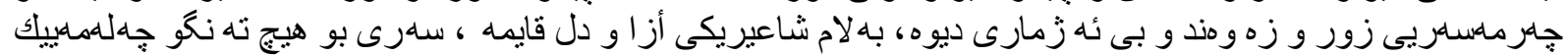

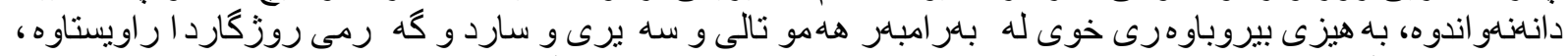

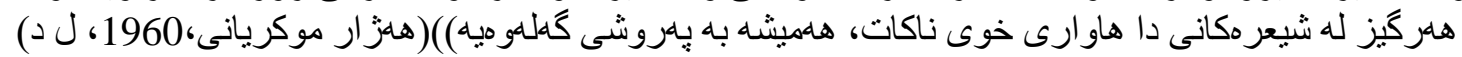

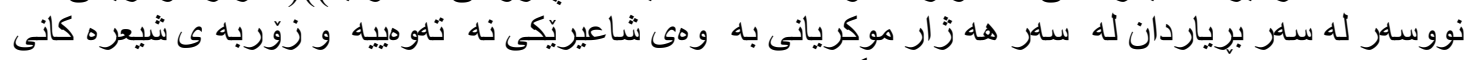

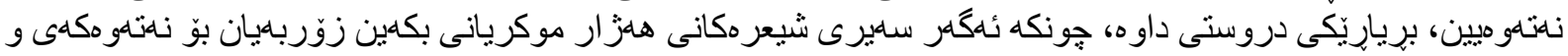

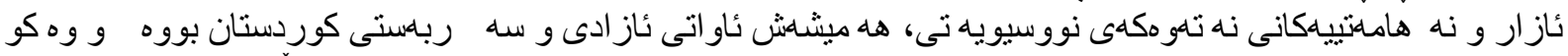

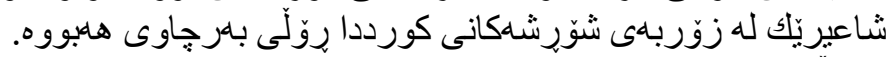

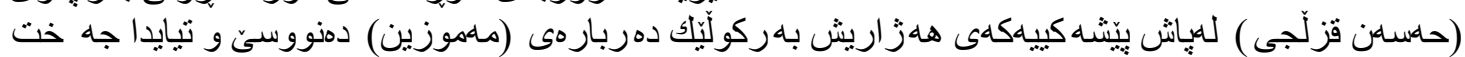

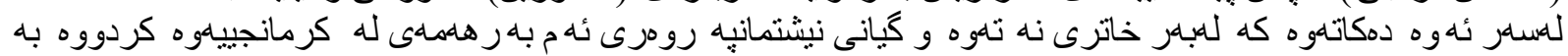

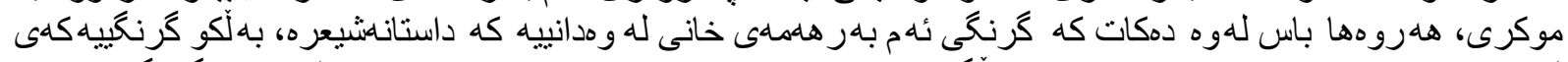

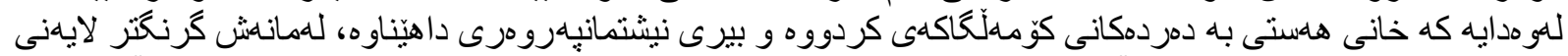

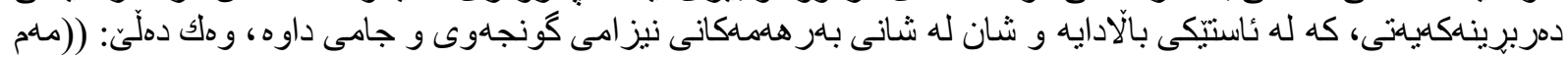




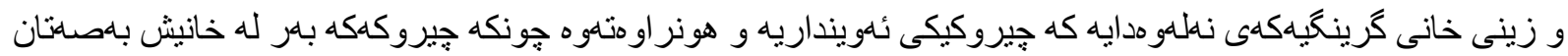

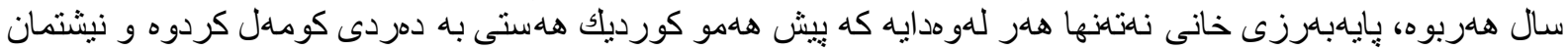

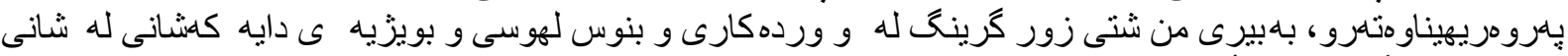

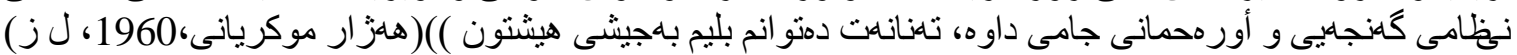

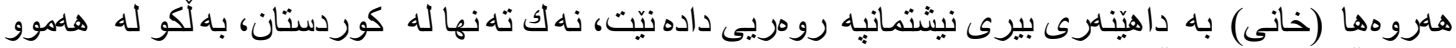

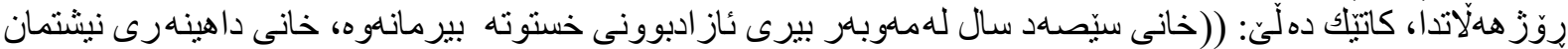

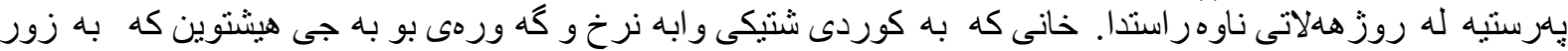

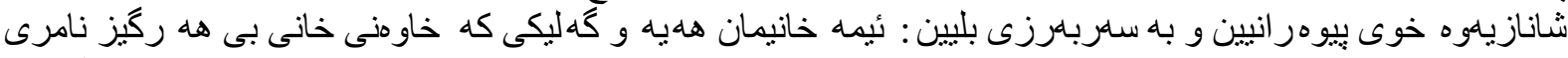

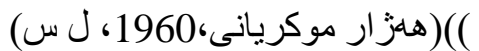

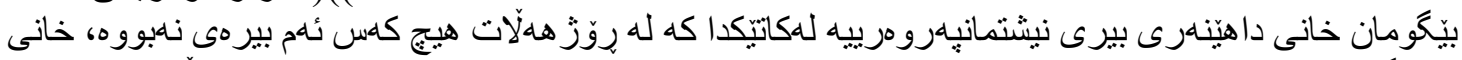

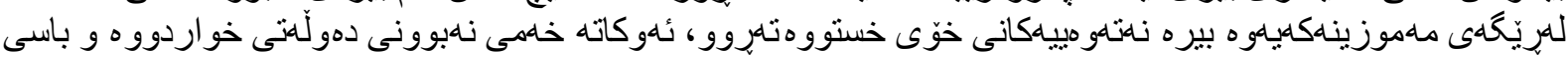

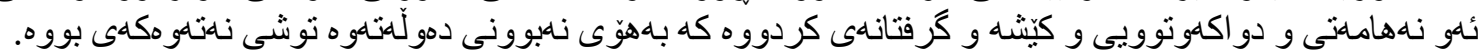

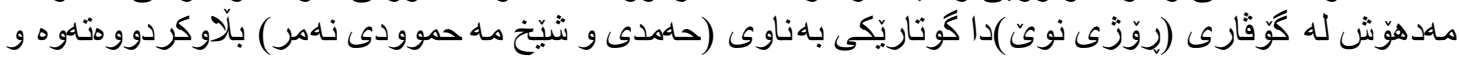

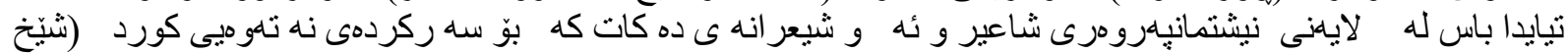

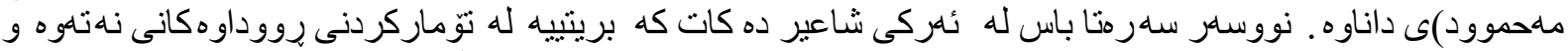

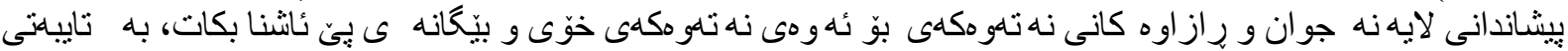

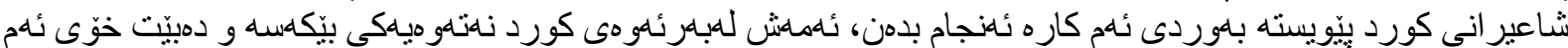

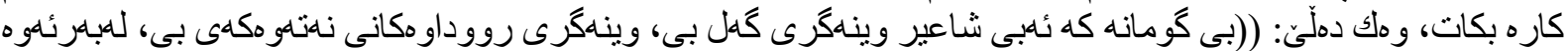

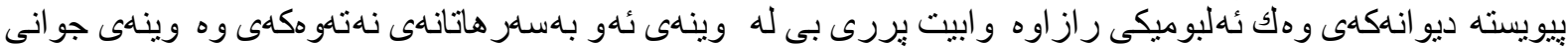

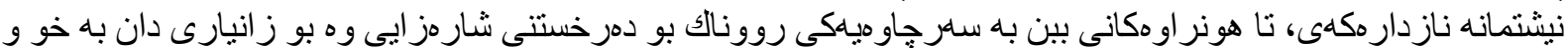

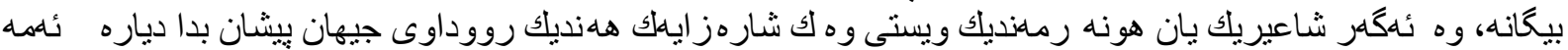

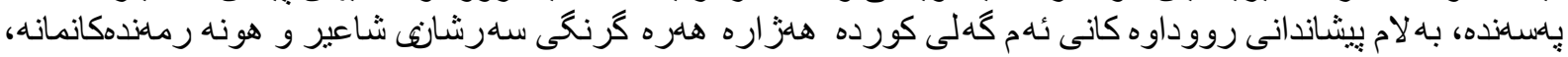

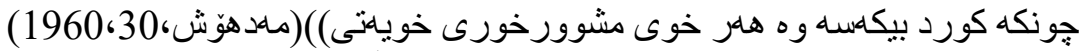

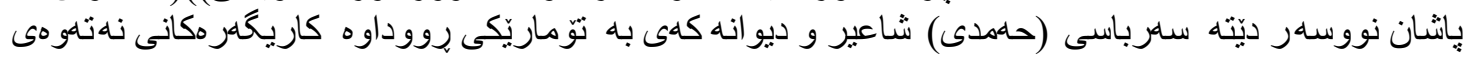

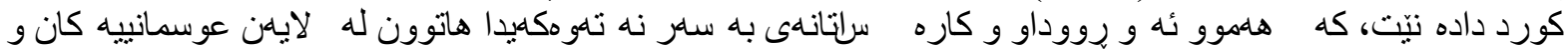

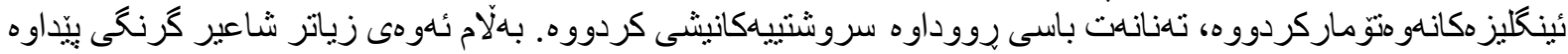

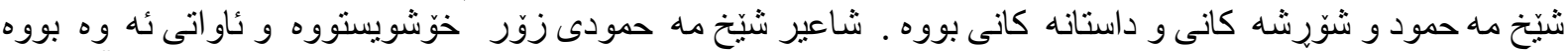

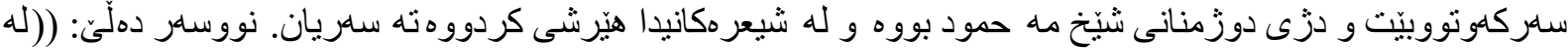

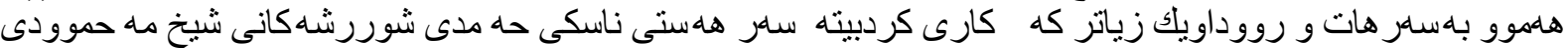

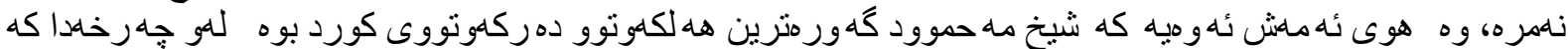

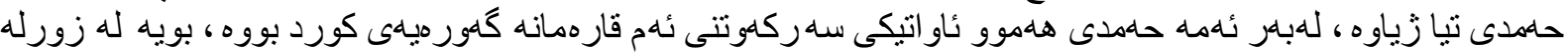

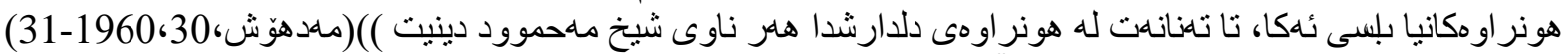

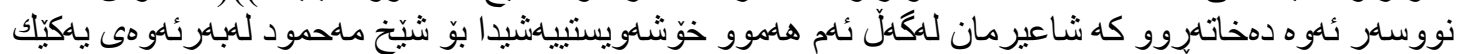

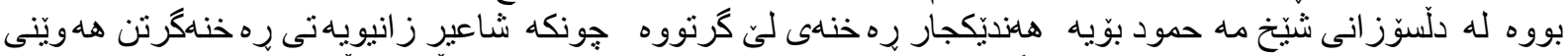

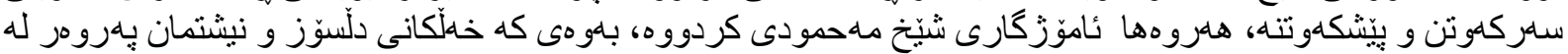

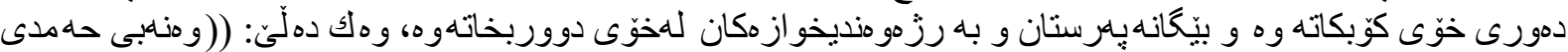

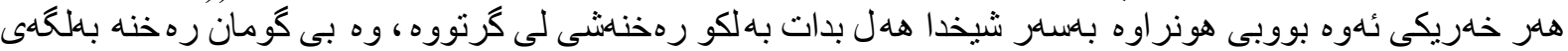

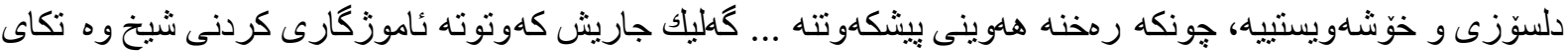

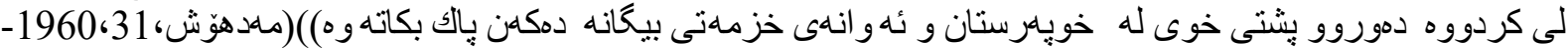

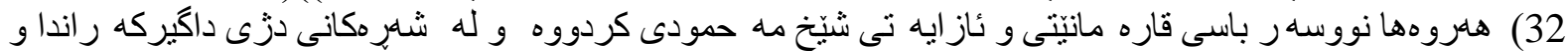

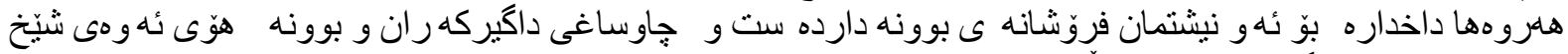

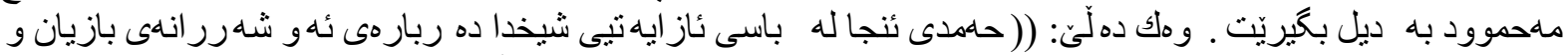

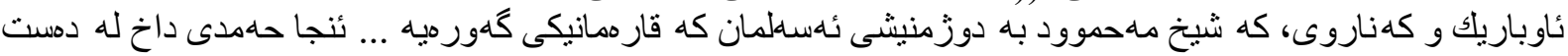

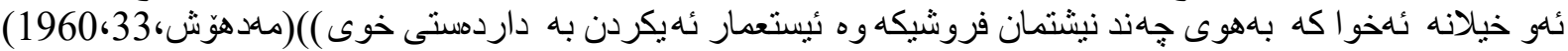

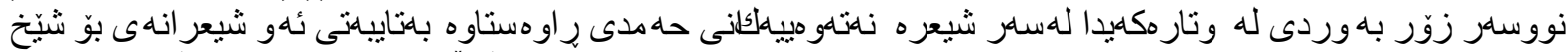

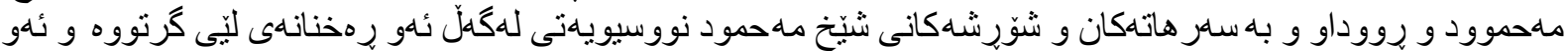

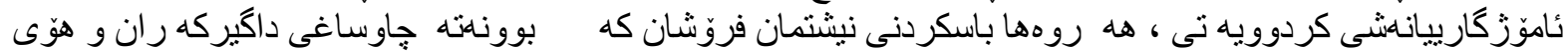

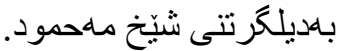

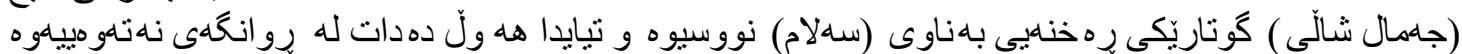

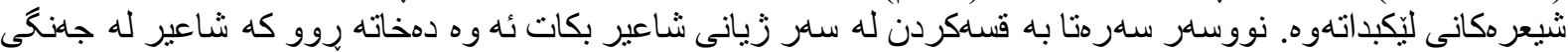




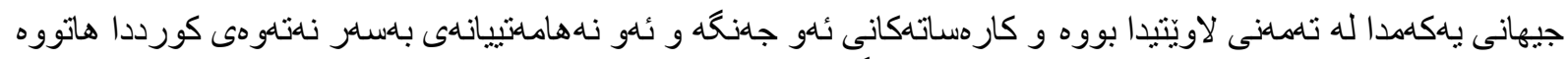

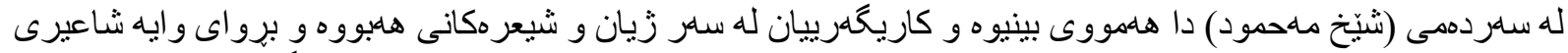

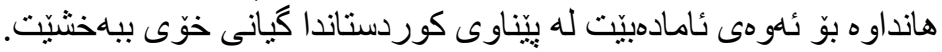

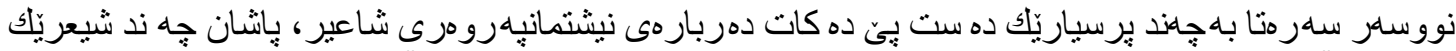

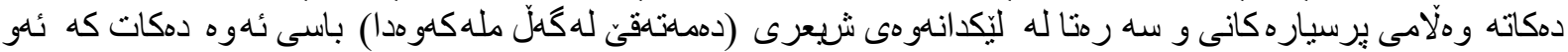

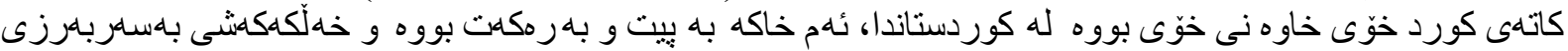

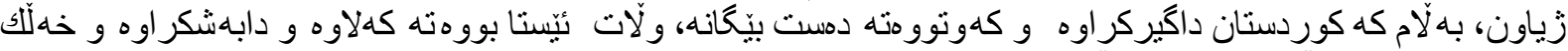

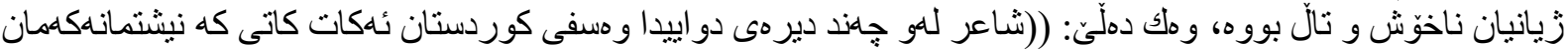

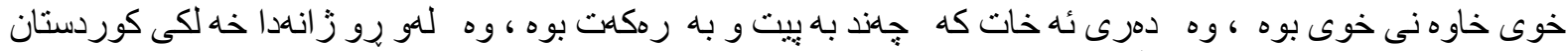

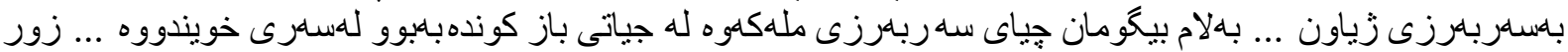

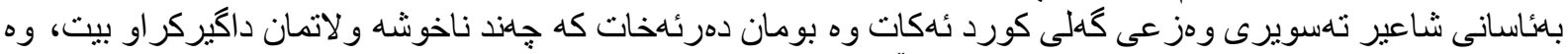

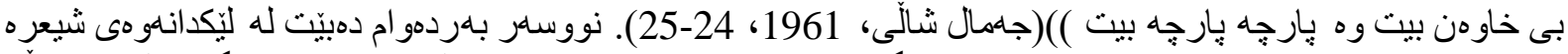

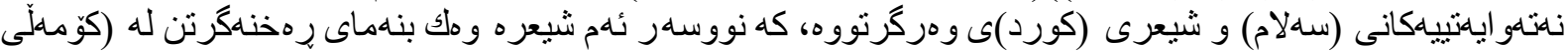

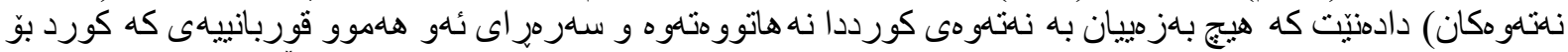

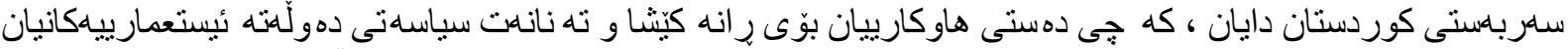

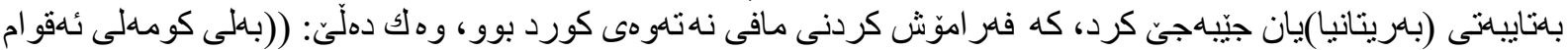

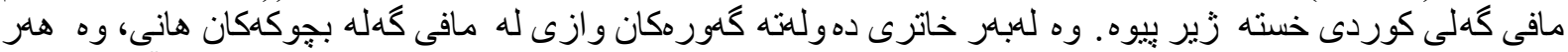

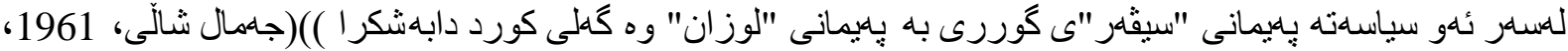
$(26$

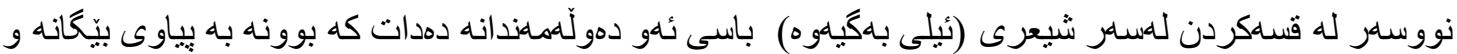

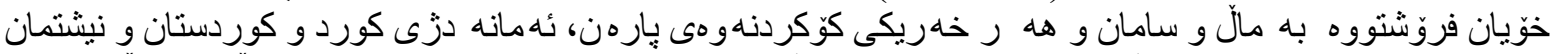

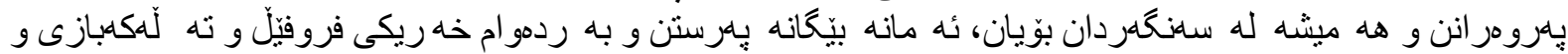

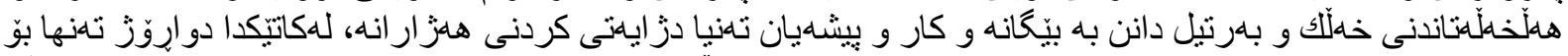

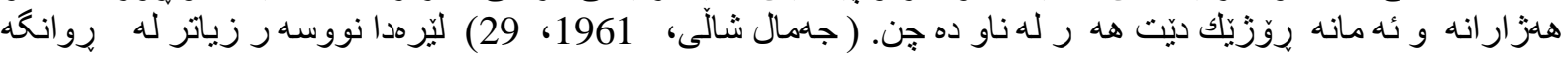

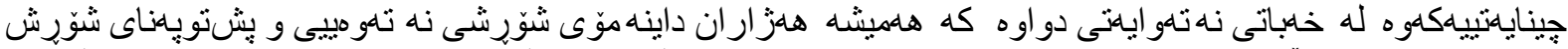

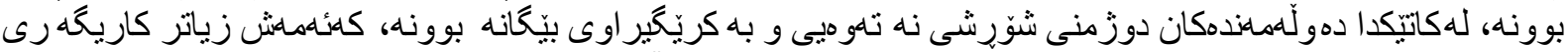

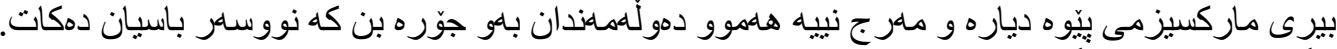

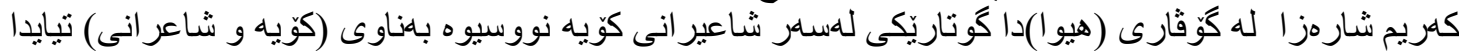

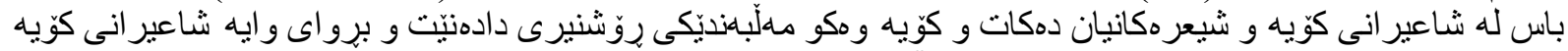

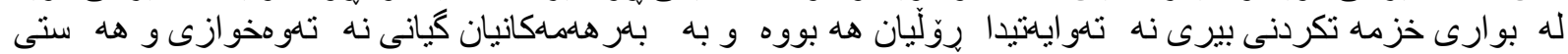

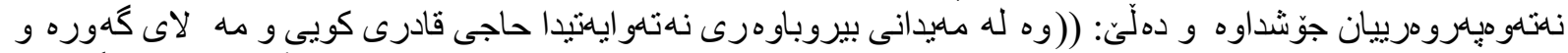

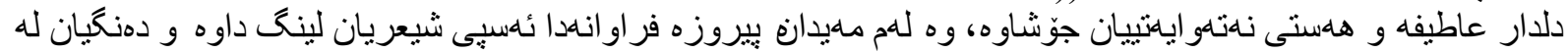

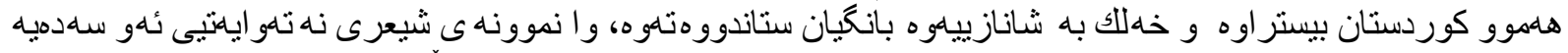

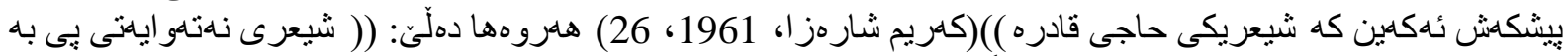

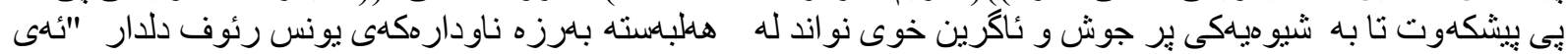

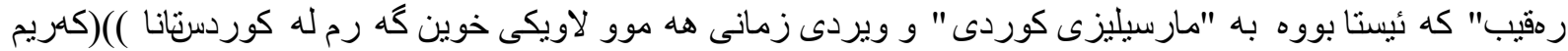

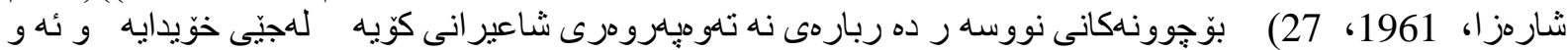

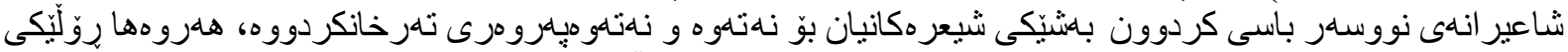

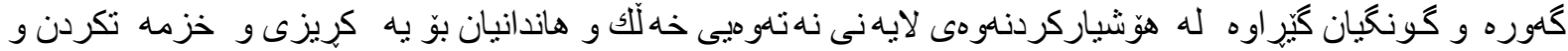

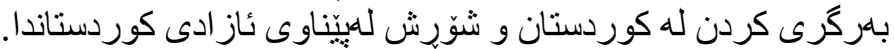

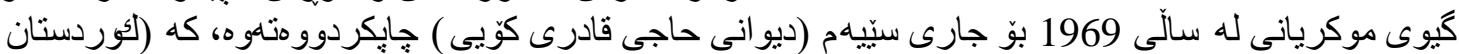

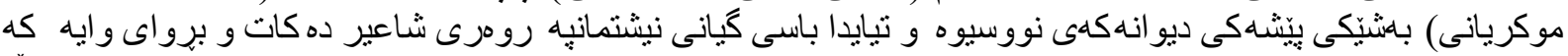

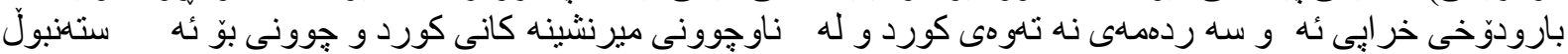

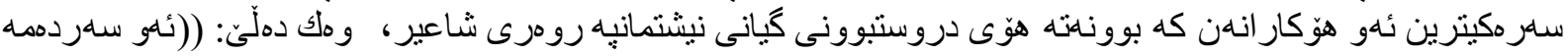

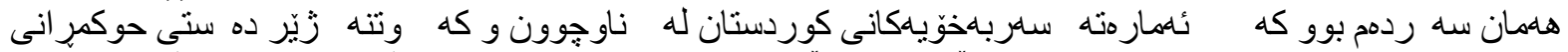

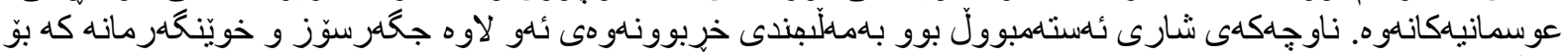

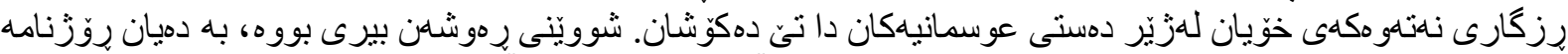

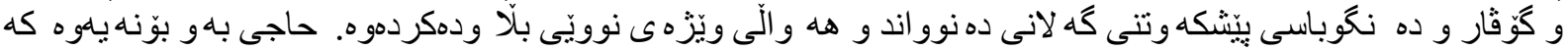

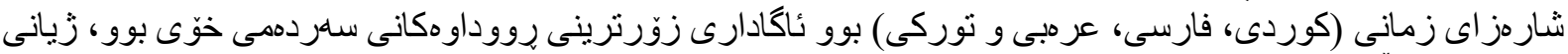

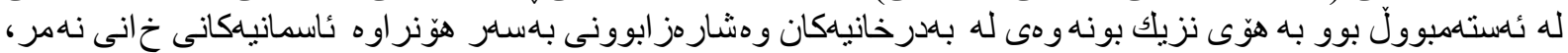




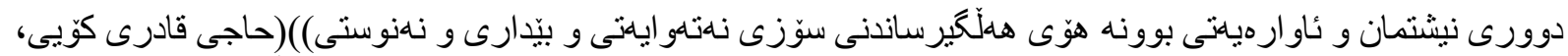

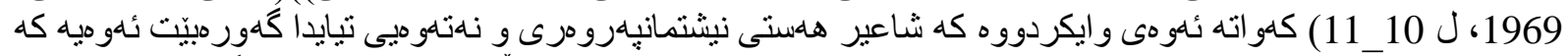

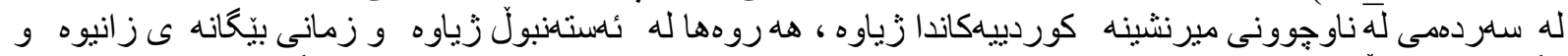

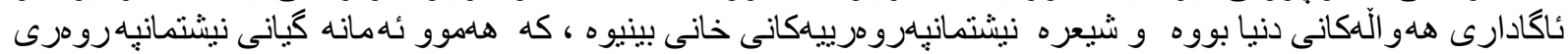

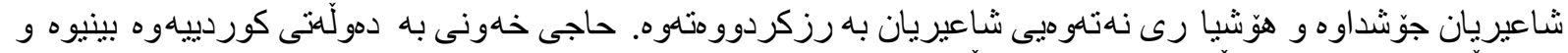

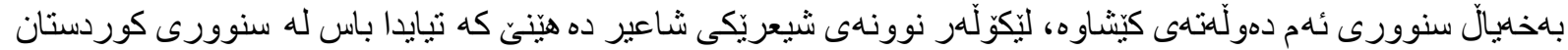

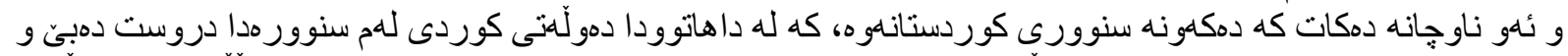

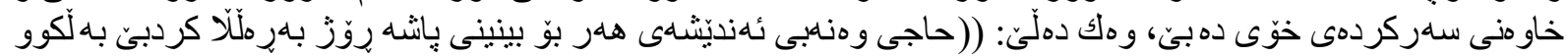

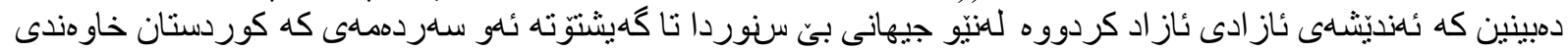

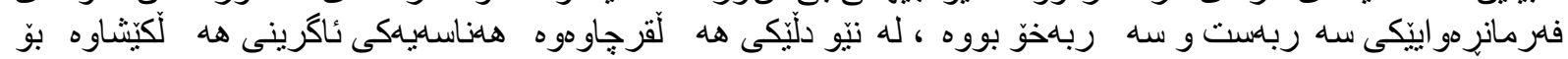

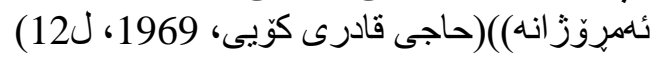

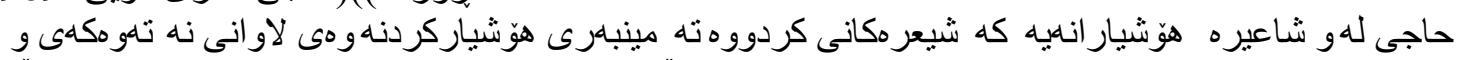

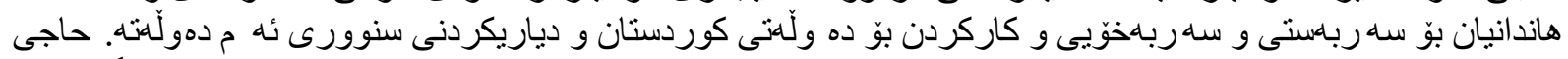

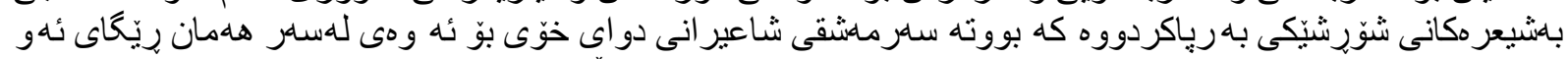

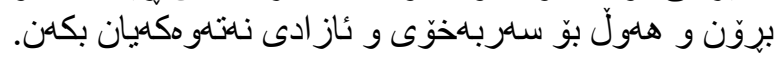

ئنسام بكان

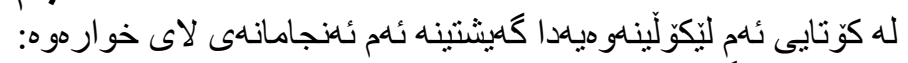

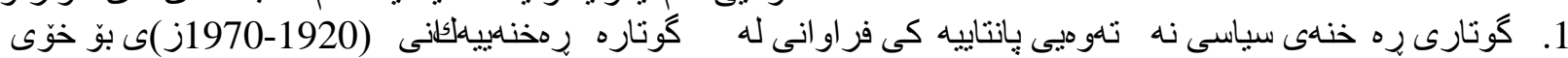
داكيركردووه هون.

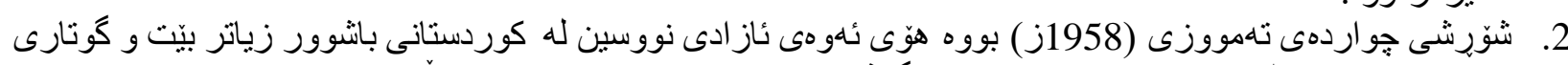

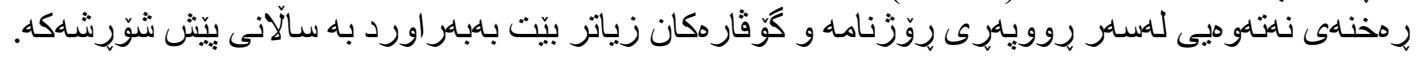

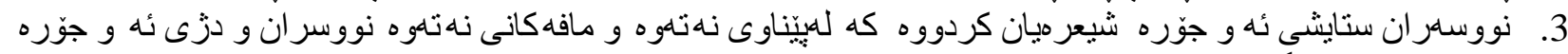

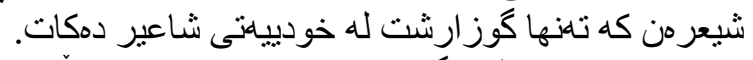

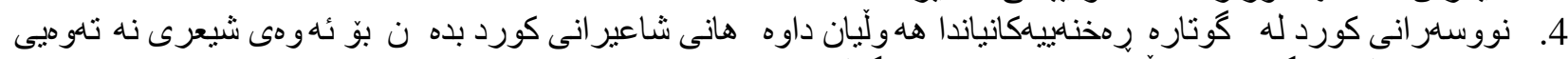

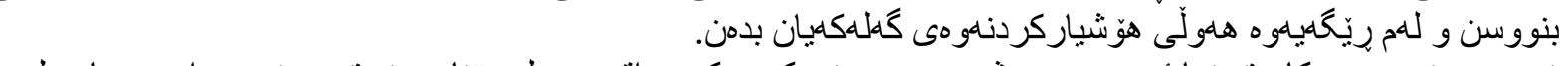

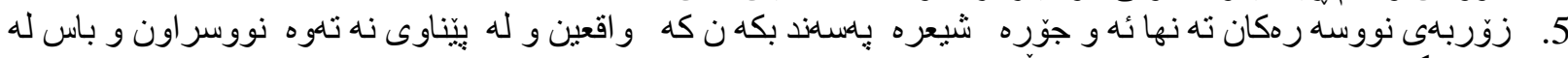
سدرجاو وكان

كنئب

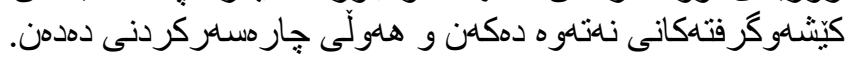

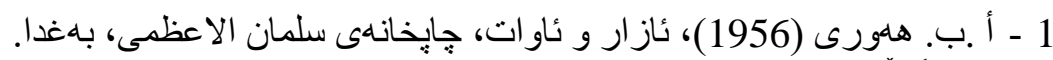

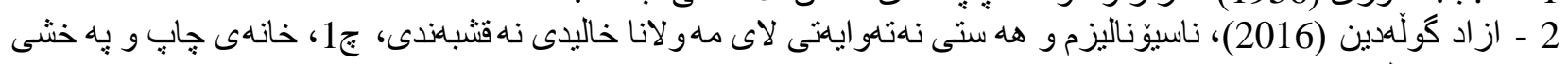
رِيَنما، سليّمانى.

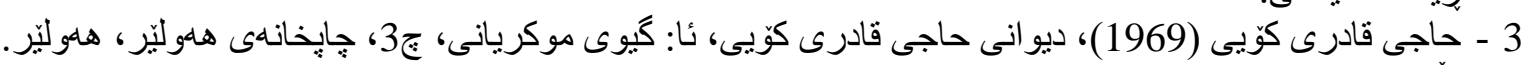

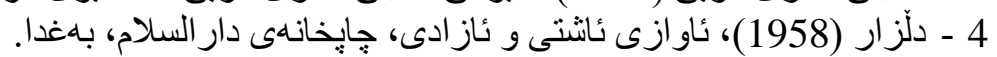

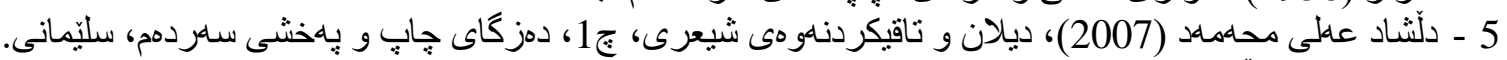

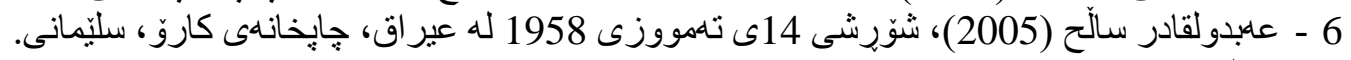

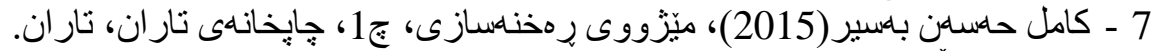

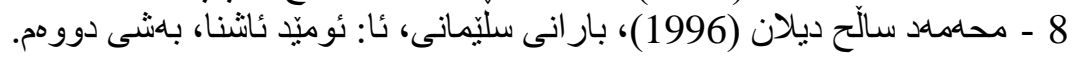
كَّ قُار و روَزْنامها

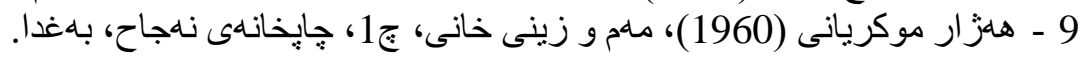

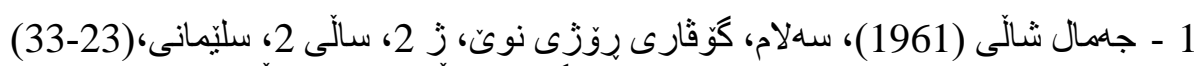

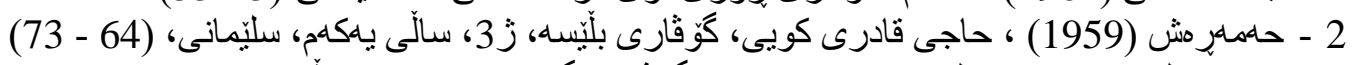

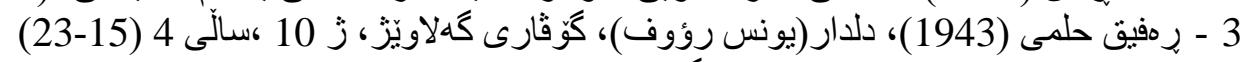

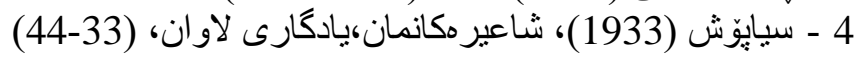

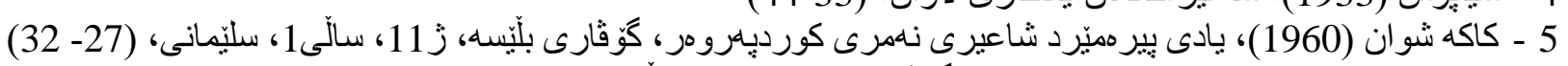

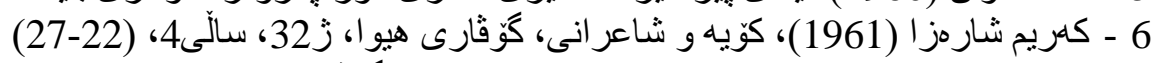

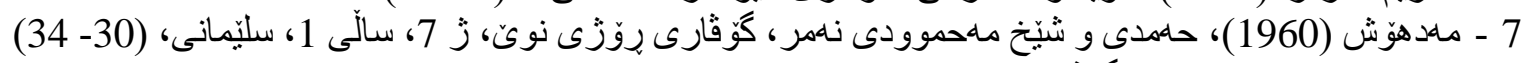

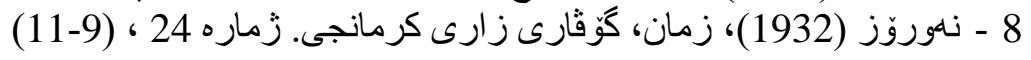




\section{REFERENCES}

\section{Books}

Abdulqadr S. (2005). The revolution of 14 July 1958 in Iraq, Karo publishing house, Slemani.

Azad Guladin, (2016). Nationalism by Mawlana Khalidi Naqshbandi, First Edition, Renma publishing house, Slemani.

Dilan, Muhamad Salih, (1996). Rain of Slemani by Omed Ashna, Second part.

Dilzar, (1958). Cantus of of peace and freedom, Darlsalam publishing house, Baghdad.

Dlshad, Ali, (2007). Dilan and poetry experiment, First Edition, Sardam publishing house, Slemani.

Hawri, A.B. (1956). Pain and hope, Salman Al Aezami publishing House.

Hazhar, Mukryani,(1960). Mam and Zin of Khani, First Edition, Najah publishing house, Baghdad.

Kamil, Hassan Basir, (2015). History of criticism, First Edition, Tehran publishing house, Tehran.

Koyi, Haji Qadri (1969). Haji Qadri koyi Divan, by Giwe Mukryani, Third Edition, Hawler publishing house, Hawler.

\section{Journals and Newspapers}

Jamal Shalli, peace, Rozhi Nwe journal, No, 2, year 2, Slemani, 1961.

Hama Rash, Haji Qadri Koyi, Blesa journal, No, 3, year 1, Slemani, 1959.

Rafiq Hilmi, Dildar( Youns Rawf), Galawezh journal, p. 2424.

Syaposh, out poets, Zhyan journal, No, 335, 336, Akhstos and Aylul, Slemani, 1932.

Kaka Shwan, souvenir of Peramerd, Blesa journal, No, 11, year 1, Slemani, 1960.

Karim sharaza, Koya and its poets, Hiwa journal, No, 32, year 4, 1961.

Madhosh, Hamdi and Shekh Mahmud, Rozhi Nwe journal, No, 7, year 1, Slemani, 1960.

Nawroz, language, Zari kurmanji journal, No, 24, 1932 